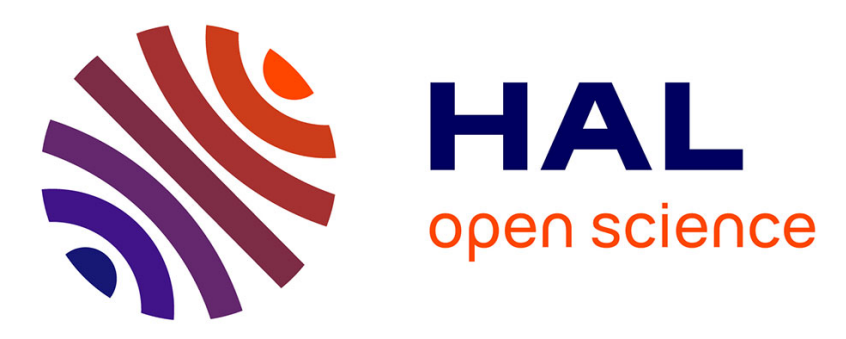

\title{
Tectonics of Enceladus' South Pole: Block rotation of the Tiger Stripes
}

Costanza Rossi, Paola Cianfarra, Francesco Salvini, Olivier Bourgeois, Gabriel

Tobie

\section{- To cite this version:}

Costanza Rossi, Paola Cianfarra, Francesco Salvini, Olivier Bourgeois, Gabriel Tobie. Tectonics of Enceladus' South Pole: Block rotation of the Tiger Stripes. Journal of Geophysical Research. Planets, In press, 10.1029/2020JE006471 . hal-03009906

\section{HAL Id: hal-03009906 https://hal.science/hal-03009906}

Submitted on 1 Dec 2020

HAL is a multi-disciplinary open access archive for the deposit and dissemination of scientific research documents, whether they are published or not. The documents may come from teaching and research institutions in France or abroad, or from public or private research centers.
L'archive ouverte pluridisciplinaire HAL, est destinée au dépôt et à la diffusion de documents scientifiques de niveau recherche, publiés ou non, émanant des établissements d'enseignement et de recherche français ou étrangers, des laboratoires publics ou privés. 


\section{Tectonics of Enceladus' South Pole: Block rotation of the Tiger Stripes}

\section{Costanza Rossi $^{1,4}$, Paola Cianfarra ${ }^{1,3}$, Francesco Salvini ${ }^{1}$, Olivier Bourgeois ${ }^{2}$, Gabriel Tobie $^{2}$}

${ }^{1}$ GeoQuTe Lab, Dipartimento di Scienze, Università degli Studi Roma Tre, Rome, Italy.

${ }^{2}$ Laboratoire de Planétologie et Géodynamique, UMR 6112, CNRS, Université de Nantes, France.

${ }^{3}$ DISTAV, Università degli Studi di Genova, Genoa, Italy.

${ }^{4}$ Istituto Nazionale di Fisica Nucleare, Laboratori Nazionali di Frascati (INFN-LNF), Frascati, Italy.

Corresponding author: Costanza Rossi (costanza.rossi@uniroma3.it) (costanza.rossi@lnf.infn.it)

\section{Key Points:}

- Tectonic activity at Enceladus' south pole is consistent with clockwise block rotation tectonics.

- Regional right-lateral strike-slip kinematics induces transtensional and transpressional regimes in the south polar region.

- An evolutionary tectonic model is proposed for the past, present and future settings of Enceladus' south polar structures.

This article has been accepted for publication and undergone full peer review but has not been through the copyediting, typesetting, pagination and proofreading process, which may lead to differences between this version and the Version of Record. Please cite this article as doi: 10.1029/2020JE006471. 


\begin{abstract}
The South Polar Terrain (SPT) of Enceladus is a site with eruptions of gas and water ice particle plumes, which indicate internal geodynamic activity. These eruptions are located along a series of tectonic structures, i.e. the Tiger Stripe Fractures (TSF), which are composed of regularly spaced, linear depressions. The SPT is surrounded by sinuous chains of ridges and troughs (the Marginal Zone). To unravel the tectonics that affect the region and its evolution, we performed specific structural mapping and quantitative analyses of brittle features from remotely-sensed images. The results are consistent with a block rotation model, in which several tectonic regimes coexist. The TSF are left-lateral strike-slip faults that bound rigid elongated blocks. The blocks rotate clockwise and are enclosed in a regional scale right-lateral kinematic framework expressed in the Marginal Zone. These two opposite and complementary kinematic regimes induce transtensional and transpressional regimes within the SPT. An evolutionary tectonic model is proposed for the past and future evolution of the SPT. This model confirms the role of tectonicrelated kinematics in icy satellites and contributes to preparations for future missions.
\end{abstract}

\title{
Plain Language Summary
}

The South Pole of Enceladus is one of the most tectonically active regions in the outer solar system. It presents morphotectonic structures that play a key role in the investigation of the internal processes responsible for its crustal deformation and represent possible interaction with the subsurface ocean. In this contribution, we investigate the Enceladus South Polar Terrain (SPT) structures that are mainly represented by the Tiger Stripe Fractures. Their tectonic setting and kinematics are the object of the present study. The results obtained allow inference of block rotation tectonics induced by regional strike-slip kinematics in the SPT. We propose an evolutionary tectonic model that presents past and future arrangements of the SPT. New findings have allowed identification of a significant compressional component within the study area, as well as the kinematics within this terrain.

This article is protected by copyright. All rights reserved. 


\section{Introduction}

Observations of water vapor and ice-crystal plumes emanating from the south polar region of Enceladus are among the most striking discoveries of the Cassini-Huygens Mission (e.g. Hansen et al., 2006; Porco et al., 2006; Spencer et al., 2006). This plume activity is associated with tectonically and thermally active terrains, witnessing strong interactions with the interior dynamics. Both chemical and geophysical measurements performed by the Cassini spacecraft imply that this activity is most likely related to the existence of a liquid salty layer at relatively shallow depth underneath the icy crust at the south pole which is possibly associated with hydrothermal activity at the seafloor (Collins \& Goodman, 2007; Choblet et al., 2017; Hsu et al. 2015; Iess et al., 2014; Postberg et al. 2009, 2011; Sekine et al. 2015; Thomas et al., 2016; Waite et al. 2017). This internal activity, which is powered by tides, produces surface deformation that includes brittle tectonics. Several fractures and faults that regionally deform the icy crust play a key role in understanding the active tectonic and geodynamic processes of the satellite (Crow-Willard \& Pappalardo, 2015; Lucchetti et al., 2017; Porco et al., 2006; Yin \& Pappalardo, 2015). The main fractures of Enceladus are the Tiger Stripe Fractures (TSF), which are located in the South Polar Terrain (SPT) and are sites of plume eruptions (Fig. 1; CrowWillard \& Pappalardo, 2015; Porco et al., 2006). The TSF and other fractures which are surrounded by a peripheral chain of ridges and valleys characterize the SPT region (Fig. 1) and represent weakness zones and potential connections between the surface and underlying ocean (Lucchetti et al., 2017; Souček et al., 2019).

Unravelling SPT kinematics is still an open issue. Several authors have interpreted the formation of the TSF as a result of tidal heating (e.g. Nimmo et al., 2007), thermal anomaly (e.g. Gioia et al., 2007), non-synchronous rotation of the icy shell above the ocean (e.g. Patthoff \& Kattenhorn, 2011), and true polar wandering (e.g. Matsuyama \& Nimmo, 2008; Tajeddine et al., 2017). These processes are possibly responsible for SPT kinematic evolution in which the TSF were produced by extension accommodated by contraction along the SPT margin (e.g. Helfenstein et al., 2006, 2008; Porco et al., 2006; Spencer \& Nimmo, 2013). This interpretation leaves open the issue of the kinematic incompatibility between the SPT marginal zone and extensional TSF.

Tectonic models have recently been proposed to elucidate this issue (e.g. Crow-Willard \& Pappalardo, 2015; Yin \& Pappalardo, 2015) in which the SPT structures initiated flow tectonics that propagated along a detachment from extensional zones (LEM in Fig. 1) to compressional

This article is protected by copyright. All rights reserved. 
ones (TEM in Fig. 1). On the other hand, in this model, the TSF play a secondary role and are identified by unclear kinematics. In addition, according to this model, TSF are unable to crosscut the entire icy shell to reach the most obvious plume sources and fluid propagation across these faults would not be favored. This assumption could be misleading since they represent the main elements in the SPT region and they more plausibly play a primary role in its tectonic process. The relationships, roles and causes for the development of tectonic structures in the SPT thus need clarification and further investigations which focus on the dynamics and kinematics of SPT tectonics. In this manner, this work attempts to contribute to this scientific debate and we explore this region by using innovative approach. By means of structural mapping based on remotely sensed data, which is coupled with statistical quantitative analyses and lineament domain analysis, we investigated the tectonic effects to reconstruct the kinematic process that deforms the SPT region. We propose a kinematic model that frames the spatial distribution of the observed evidence of brittle deformation and its evolution.

This article is protected by copyright. All rights reserved. 


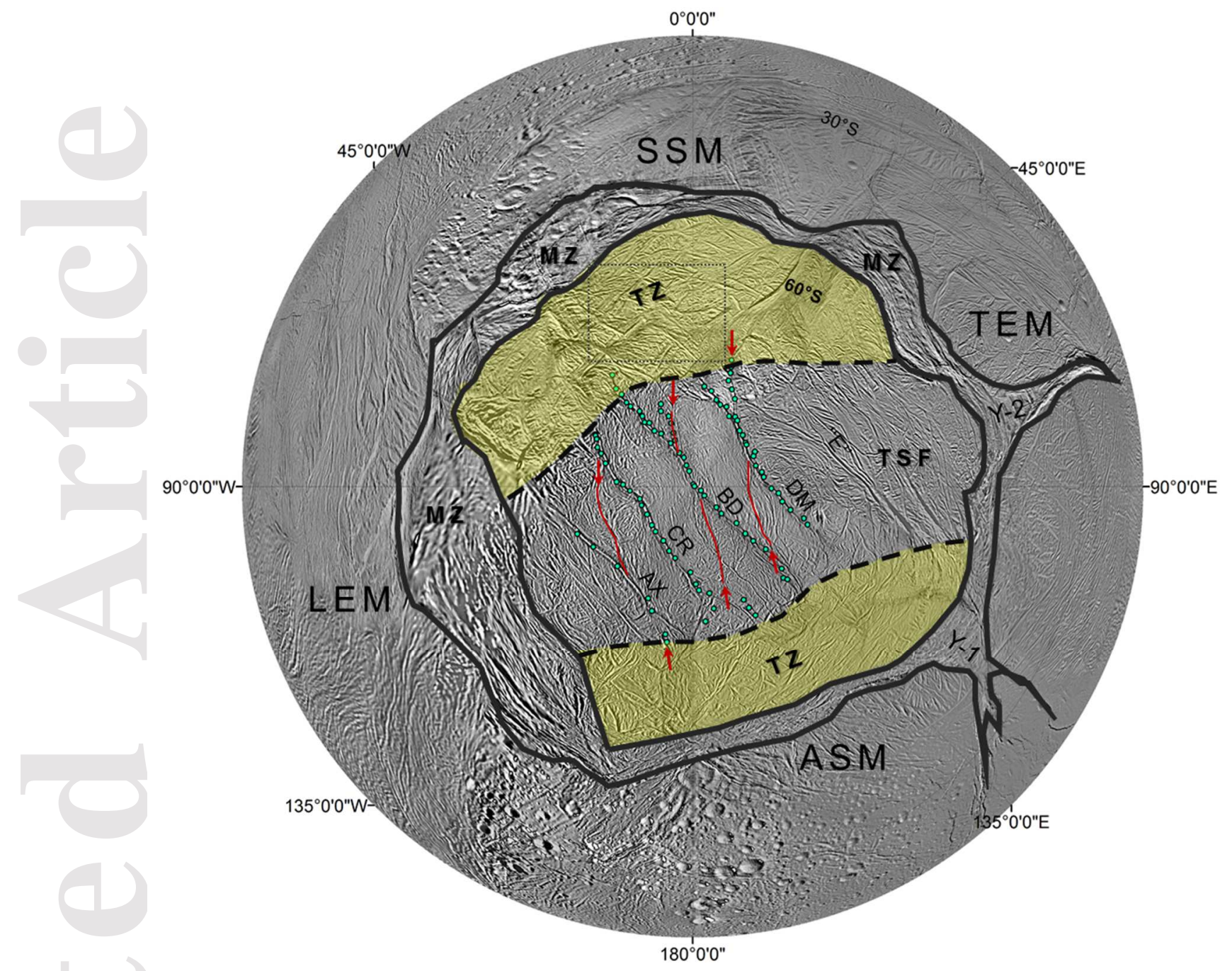

Figure 1. Enceladus South Polar Terrain (SPT), USGS Enceladus global mosaic orthographic projection. Tiger Stripe Fractures (TSF: Alexandria Sulcus, AX; Cairo Sulcus, CR; Baghdad Sulcus, BD; Damascus Sulcus, DM; and fracture zone "E") are located in the center of the SPT. The light-green dots represent plume source locations (Porco et al., 2014). The red arrows and lines indicate the location and the orientation of ancient Tiger Stripes (Patthoff \& McKinnon, 2011). The structural units are illustrated. The dark-grey lines depict the Marginal Zone (MZ) and its edges: Leading-edge Margin (LEM), Trailing-edge Margin (TEM), Sub-Saturnian Margin (SSM), and Anti-Saturnian Margin (ASM) (Yin \& Pappalardo, 2015); the yellow areas show the Transitional Zone (TZ); the dashed black lines border the Tiger Stripe Fractures (TSF) structural unit. The Y-shaped structures (Y-1 and Y-2) are shown at the TEM edge. The dotted square indicates the location of Fig. 5.

\section{Geological and structural setting}

Enceladus is a satellite of Saturn with a radius of $252.1 \pm 0.2 \mathrm{~km}$ (Porco et al., 2006). It is located in the external E ring of Saturn and contributes to its replenishment with the eruptive material from the plumes emanating from its south polar region (Helfenstein \& Porco, 2015; Porco et al., 
2006, 2014). The plumes are composed of water vapor, ice particles, and organic compounds (Filacchione et al., 2016; Gioia et al., 2007; Helfenstein \& Porco, 2015; Hendrix et al., 2010; Johnston \& Montési, 2017; Matson et al., 2007; Porco et al., 2006; Potsberg et al., 2018; Roberts, 2016; Scipioni et al., 2017; Thomas et al., 2016). These are possibly produced by water boiling and/or ice sublimation at or below the surface (Porco et al., 2006) and indicate internal activity of the satellite which is affected by tidal heating (Beuthe, 2016; Čadek et al., 2016; Choblet et al., 2017; Schenk \& McKinnon, 2009; Thomas et al., 2016; Tobie et al., 2008).

Gravity, topography and rotational data collected by Cassini indicate that the interior is subdivided, from top to bottom, into (i) a water ice shell with an average thickness of 20-25 km (Thomas et al. 2016) that decreases to possibly less than $5 \mathrm{~km}$ beneath the south pole (Beuthe et al. 2016; Čadek et al., 2016; Hemingway et al. 2018; LeGall et al., 2017) and possibly exceeds 30-35 km in some equatorial regions (Čadek et al., 2016, 2019; Lucchetti et al., 2017; Patthoff \& Kattenhorn, 2011; Schenk \& McKinnon, 2009); (ii) a regional (Collins and Goodman, 2007; Iess et al., 2014; McKinnon, 2015; Spencer \& Nimmo, 2013; Tobie et al. 2008) or global (Choblet et al., 2017; McKinnon, 2015; Patthoff \& Kattenhorn, 2011; Thomas et al., 2016) liquid ocean with low salinity (Čadek et al. 2016; Postberg et al. 2009) which is composed of water mixed with ammonia (Porco et al., 2006) and is 20-70 km thick (Johnston \& Montési, 2017; Patthoff \& Kattenhorn, 2011) and (iii) a low density, porous rocky core which is approximately $180-190 \mathrm{~km}$ in radius (Beuthe 2016; Čadek et al., 2016; Iess et al. 2014; Johnston \& Montési, 2017; McKinnon 2015; Roberts, 2016).

Spectral data collected by the Visible and Infrared Mapping Spectrometer, VIMS, instrument onboard Cassini indicate that the surface of Enceladus is mostly composed of water ice, organic compounds and trapped $\mathrm{CO}_{2}$ (Brown et al., 2006; Combe et al. 2019; Robidel et al. 2020, Scipioni et al. 2017). Brittle deformation has occurred during Enceladus' history and formed regional-scale landforms by tectonic activity, which are called morphotectonic structures or tectonic structures in this study.

A total of three main regions of deformation, each containing multiple structural units, have been recognized on a global scale. These are the South Polar Terrain (SPT), Leading Hemisphere Terrain (LHT) and Trailing Hemisphere Terrain (THT) (Crow-Willard \& Pappalardo, 2015). They display similar morphological and structural settings where a belt of ridges and troughs circumscribes the deformed units. The region investigated in this work is the SPT region, which

This article is protected by copyright. All rights reserved. 
is an area of approximately $70,000 \mathrm{~km}^{2}$ that extends from $50^{\circ} \mathrm{S}$ to the south pole. It represents the youngest terrain of Enceladus with an age possibly not more than $0.5 \mathrm{Ma}$ (Crow-Willard \& Pappalardo, 2015; Porco et al., 2006; Yin \& Pappalardo, 2015) and crustal thickness of possibly less than 5 km (Čadek et al., 2016; Helfenstein \& Porco, 2015; Johnston \& Montési, 2017; Le Gall et al., 2017; Olgin et al., 2011). The origin of activity occurring in this terrain is still an open debate. Tidal heating (Beuthe, 2016; Choblet et al., 2017; Crow-Willard \& Pappalardo, 2015; Patthoff \& Kattenhorn, 2011; Schenk \& McKinnon, 2009; Scipioni et al., 2017; Thomas et al., 2016; Tobie et al., 2008) may coexist with other processes such as convection (Barr, 2008; Crow-Willard \& Pappalardo, 2015), crystallization of the internal ocean (Johnston \& Montési, 2017), hydrothermal activity (Čadek et al., 2019; Choblet et al., 2017; Hsu et al., 2015), and polar wandering (Matsuyama \& Nimmo, 2008; Nimmo \& Pappalardo, 2006; Tajeddine et al., 2017).

The SPT can be subdivided into three structural units (Fig. 1). These are (i) the Marginal Zone, a circumferential belt of ridges that surrounds the region (Yin \& Pappalardo, 2015); (ii) the Tiger Stripe Fractures unit; and (iii) the zone that occurs between two edges of the Marginal Zone and Tiger Stripe Fractures unit. This structural unit is called the Transitional Zone.

\subsection{The Marginal Zone}

The Marginal Zone comprises a complex pattern of sinuous subparallel ridges and troughs (Fig. 1). This belt is nearly rectangular in shape. Part of this unit refers to the outer unit (i.e. the Southern Curvilinear unit) of Crow-Willard and Pappalardo (2015) and it is formed by four different margins that consist of the Leading-edge Margin (LEM, between $60^{\circ} \mathrm{W}-160^{\circ} \mathrm{W}$ ); Trailing-edge Margin (TEM, between $40^{\circ} \mathrm{E}-120^{\circ} \mathrm{E}$ ); Anti-Saturnian Margin (ASM, between $120^{\circ} \mathrm{E}-160^{\circ} \mathrm{W}$ ); and Sub-Saturnian Margin (SSM, between $60^{\circ} \mathrm{W}-20^{\circ} \mathrm{E}$ ) according to Yin and Pappalardo (2015) (Fig. 1). Two arcuate arcs of morphotectonic features (Y-shaped cracks; Yin \& Pappalardo, 2015) occur along the TEM (Y-1 and Y-2 in Fig. 1). The Marginal Zone is generally interpreted as a compressional zone (Crow-Willard \& Pappalardo, 2015; Gioia et al., 2007; Johnston \& Montési, 2017; Porco et al., 2006; Thomas et al., 2007). Yin and Pappalardo (2015) proposed the coexistence of several tectonic regimes for this structural unit. They suggested flow-like tectonics in which a basal detachment connects extensions in the LEM with compression in the TEM which is accommodated by left-lateral strike-slip kinematics at the

This article is protected by copyright. All rights reserved. 
SSM and right-lateral strike-slip at the ASM. Fig. 2 shows a schematic cross-sectional representation of this model.

\subsection{The Tiger Stripe Fractures unit}

The Tiger Stripe Fractures (TSF) represent one of the most interesting and puzzling features of Enceladus. These are four regularly spaced, linear depressions which are approximately $130 \mathrm{~km}$ long, $500 \mathrm{~m}$ deep, $2 \mathrm{~km}$ wide, and approximately $35 \mathrm{~km}$ distant from each other (Gioia et al., 2007; Porco et al., 2006) with terminal tips showing a horsetail geometry. The TSF include Alexandria Sulcus (AX), Cairo Sulcus (CR), Baghdad Sulcus (BD), and Damascus Sulcus (DM) (Helfenstein \& Porco, 2015; Porco et al., 2006; Yin \& Pappalardo, 2015; Fig. 1). These fractures possibly play a key role in connecting the surface with the liquid ocean that is estimated to exist at a depth of a few kilometers below this area (Čadek et al., 2016, 2019; Helfenstein \& Porco, 2015; Johnston \& Montési, 2017; Le Gall et al., 2017; Olgin et al., 2011). They are also locations of the plume punctual sources (Fig. 1, light-green dots; Helfenstein \& Porco, 2015; Porco et al., 2006, 2014). A possible fifth Tiger Stripe known as zone "E" (Yin \& Pappalardo, 2015) or "F" and associated with a subsurface thermal anomaly (Le Gall et al., 2017) is located between Damascus Sulcus and the TEM and is considered to be currently inactive due to a lack of observed erupting plumes (Porco et al., 2006, 2014; Le Gall et al., 2017). The absence of erupting activity in this thermally active area may be explained by a local increase of ice shell thickness (Čadek et al. 2016, 2019), preventing direct connection with the subsurface ocean. The TSF offset fractures are morphologically similar to the present-day tiger stripes. These fractures are believed to be ancient TSF, currently inactive, which suggest a long geological history of tiger-stripe-like activity in the SPT (Fig. 1, red arrows; Patthoff \& Kattenhorn, 2011). Between the TSF are intensely folded terrains called funiscular plains (Fig. 2; Barr \& Preuss, 2010; Nahm \& Kattenhorn, 2015; Spencer \& Nimmo, 2013). This structural unit is part of the inner unit (i.e. the Central South Polar Unit) proposed by Crow-Willard and Pappalardo (2015). The TSF have been interpreted either as extensional (Crow-Willard \& Pappalardo, 2015; Gioia et al., 2007; Johnston \& Montési, 2017; Thomas et al., 2007) or left-lateral strike-slip faults (Martin, 2016; Yin \& Pappalardo, 2015).

This article is protected by copyright. All rights reserved. 


\subsection{The Transitional Zone}

South of the SSM and ASM, the structural pattern and spatial distribution of the tectonic structures differ from those of both the Marginal Zone and TSF unit. These sectors, which are located between the SSM and ASM and the tips of the TSF, are densely populated by two groups of shorter and nearly orthogonal structures that intersect one another. This organization differs from that of the regions located between the LEM and TEM edges and the TSF unit. We thus propose the definition of a new structural unit in the SPT, namely the Transitional Zone, to account for the specific characteristics of these two areas (Fig. 1). This is a separately classified unit and is intermediate between the outer and inner units recognized by Crow-Willard and Pappalardo (2015).

This new classification is proposed to better separate the main and well-defined TSF from the second-order structures.

The structures that occur in this structural unit have been interpreted as continuations of the TSF which intersect the Marginal Zone (Yin \& Pappalardo, 2015).

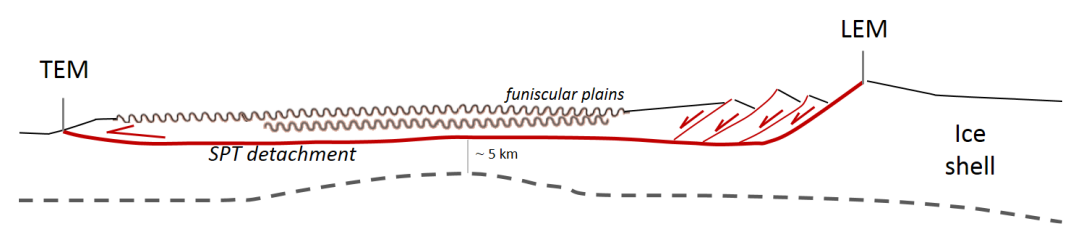

Figure 2. Cross-sectional view of the model proposed by Yin and Pappalardo (2015). A basal detachment lies under the SPT region and produces flow-like tectonics from the extensional LEM to the compressional TEM. Folding (funiscular plains; Barr \& Preuss, 2010) is present within the TSF structural unit. (Modified from Yin and Pappalardo, 2015). 


\section{Structural analyses and results}

The tectonic structures of Enceladus' SPT were mapped (section 3.1) using a geographic information system (GIS) geodatabase and were statistically analyzed by means of DAISY3 (Salvini et al., 1999) and SID software for automatic lineament identification (Cianfarra \& Salvini, 2015). The data are available in Rossi (2020). The analyses performed included spatial distributions and azimuthal analyses (sections 3.2 and 3.3) and detection of the spatial frequency of the structures (sections 3.4 and 3.5).

Azimuthal analyses were performed by means of spatial polymodal Gaussian best fit techniques that enabled identification of independent azimuthal groups both in the mapped structures (sections 3.1 and 3.2) and lineaments (section 3.3) and were automatically identified in the SPT (e.g. Cianfarra \& Salvini, 2014, 2015; Lucianetti et al., 2017; Pinheiro et al., 2019; Rossi et al., 2018; Wise et al., 1985).

Spatial frequencies were investigated to infer the periodicity of the structures related to tectonic conditions. This analysis was performed using measurements of the Length-Spacing ratio (L/S, section 3.4; e.g. Cianfarra \& Salvini, 2016a; Rossi et al., 2018; Salvini, 2013) and an ad-hoc image filtering strategy that enabled determination of the relationships between the pixel Digital Numbers (DNs) responses to morphological periodicity (section 3.5; e.g. Fossen, 2010, chapter 8; Woodward et al., 1989).

\subsection{Mapping}

A total of 354 long rectilinear-to-curvilinear structures which were related to high tonal variations were identified on the Enceladus Cassini global greyscale mosaic assembled from the Cassini Imaging Science Subsystem (ISS) images by the USGS astrogeology program (Bland et al., 2018). The spatial scale of this base mosaic ranges between 500 and $50 \mathrm{~m} /$ pixel. Although a slight bias in feature mapping may be present due to reduced resolution in some local areas, this variation only weakly affected the regional-scale mapping performed since it considers a larger scale of investigation. Regional-scale structures with high tonal intensities, which represent the main structures at the observed resolution, were digitized as polylines and were classified based on their spatial distributions into the structural units of the SPT, i.e. the Marginal Zone, Transitional Zone and TSF unit. The structures were further classified into azimuthal systems (Fig. 3) by means of quantitative statistical analyses. 
The Marginal Zone presents two systems. The first system occurs at the LEM-TEM edges (blue color in Fig. 3) and is characterized by sinuous structures while the second system is present at the SSM-ASM edges (green color in Fig. 3) with straighter structures. The Transitional Zone presents two systems which are characterized by short and straight structures (purple and red colors, respectively, in Fig. 3). Their similar crosscutting relationships suggest that they were formed by the same dynamic history. The TSF system is characterized by long structures (orange color in Fig. 3). The TSF cuts and offsets with sinistral displacements of other structures and their terminations with horsetail geometries describe an S-shape along the SSM and ASM edges.

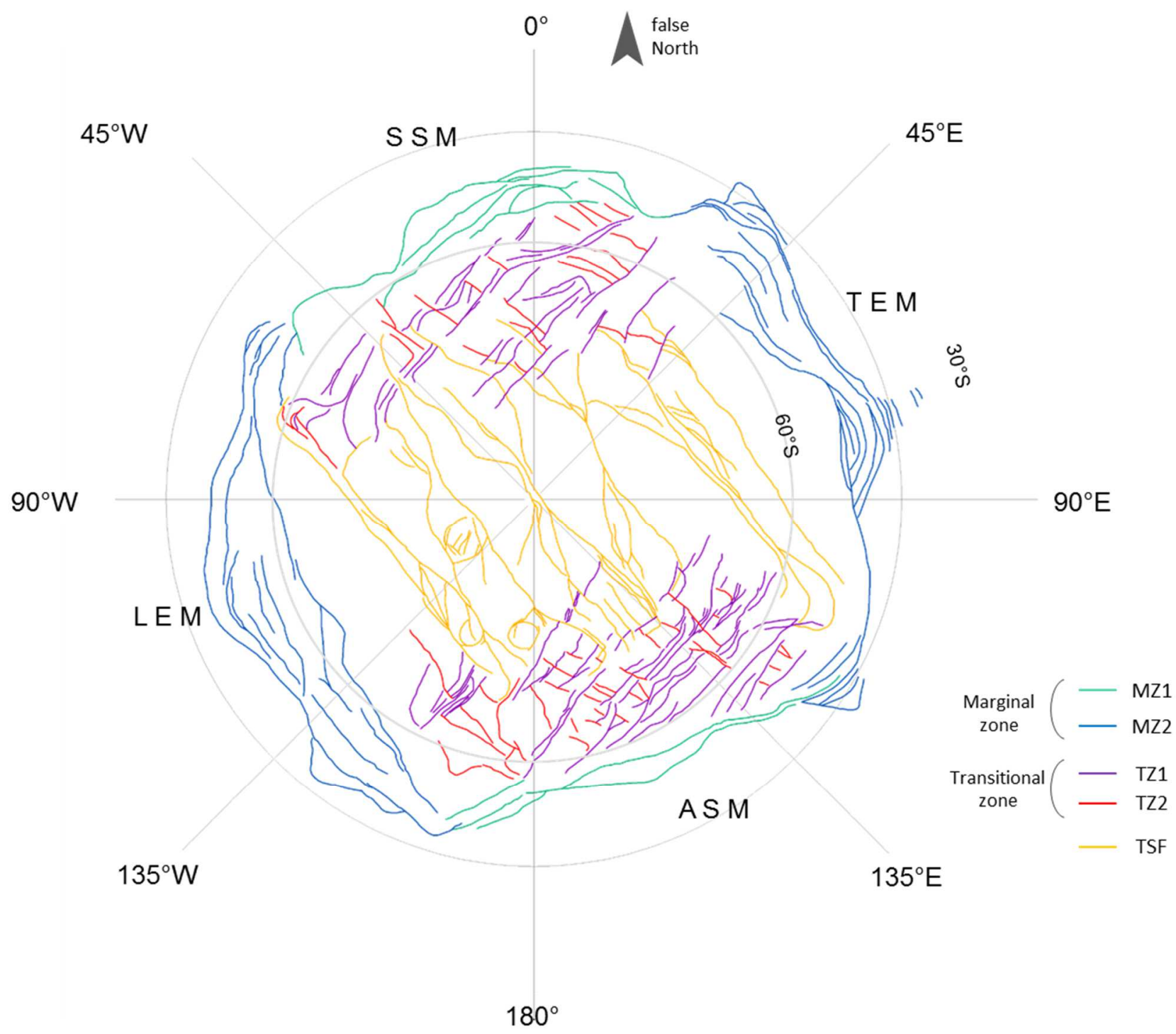

Figure 3. Enceladus SPT tectonic systems. The Marginal Zone systems are MZ1 (green) and MZ2 (blue). The Transitional Zone systems are TZ1 (purple) and TZ2 (red). The TSF system is illustrated in orange (Rossi 2020).

This article is protected by copyright. All rights reserved. 


\subsection{Azimuthal analysis}

A spatial polymodal procedure using Gaussian best fit techniques was performed for azimuthal analysis of the identified structures. Independent azimuthal groups are represented by a family of Gaussian curves (e.g. Cianfarra \& Salvini, 2016a; Maggi et al., 2015; Rossi et al., 2018; Wise et al., 1985).

We computed the azimuths of each structure and digitized these as polylines with respect to a reference of "false North" (Fig. 3). Their azimuth was defined as the orientation of the element that connects the two polyline vertices with the minimum length (Rossi et al., 2018). To characterize the orientations of these elements, azimuthal analysis was performed for frequency and cumulative length. This allowed recognition of a total of five azimuthal systems in the SPT (Fig. 4).

This article is protected by copyright. All rights reserved. 

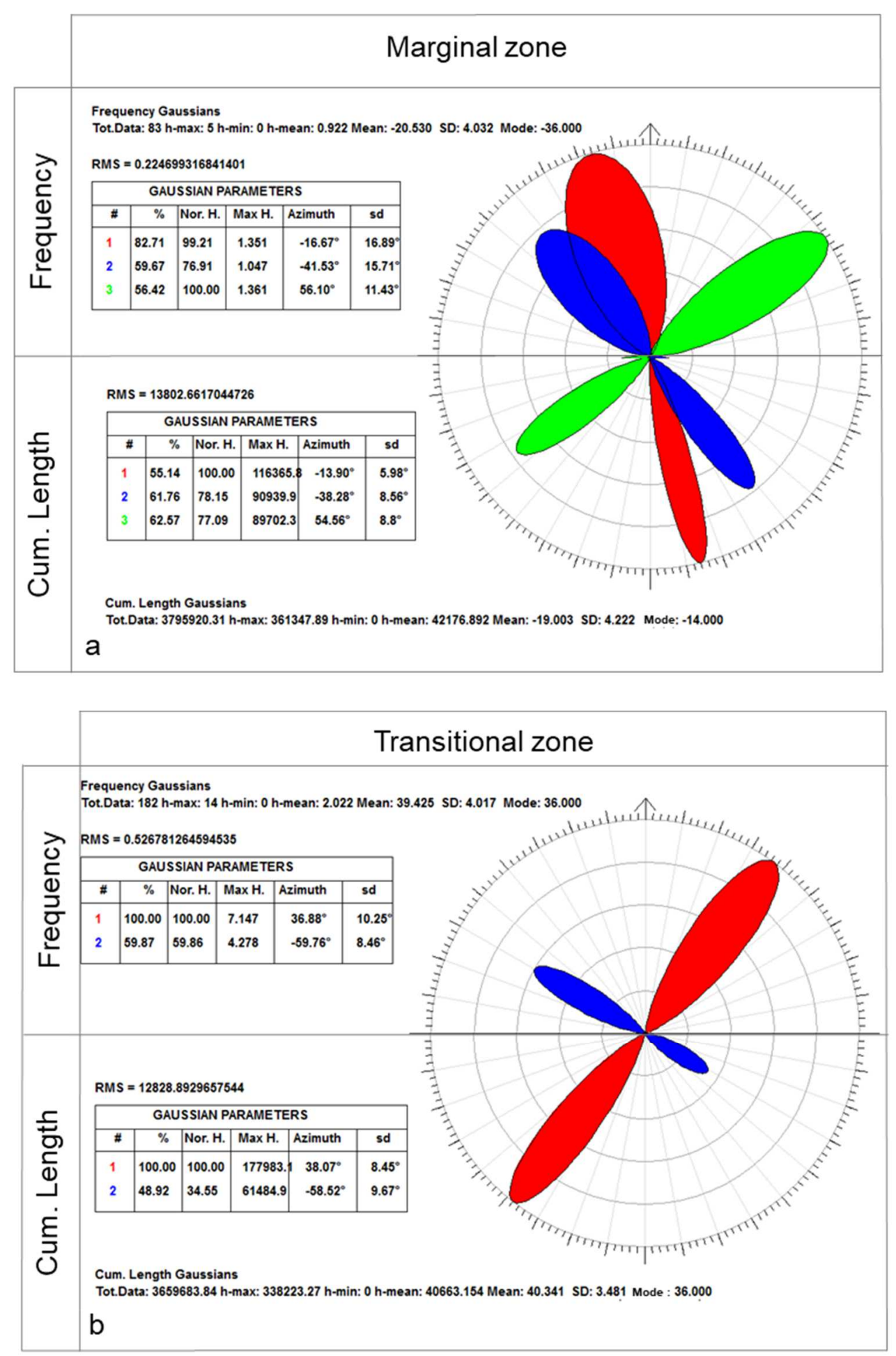

This article is protected by copyright. All rights reserved. 


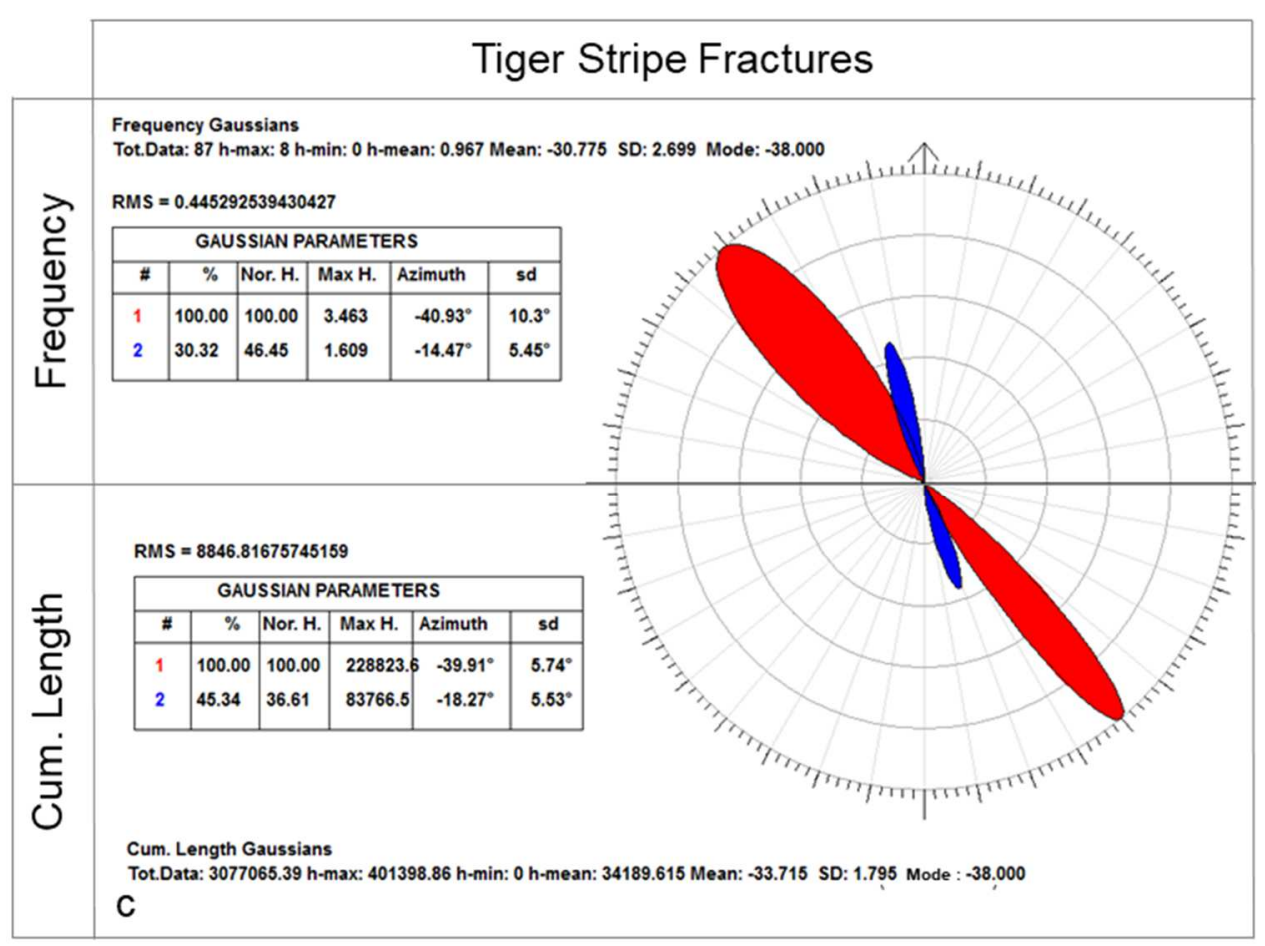

Figure 4. Azimuthal analyses of the recognized SPT systems. The wind rose diagrams were subdivided into two semicircles which show the results by frequency (upper diagram) and by cumulative length (lower diagram). Azimuthal analysis of a) Marginal Zone, b) Transitional Zone, and c) TSF structural unit. The Gaussian Parameters are: the number of Gaussian peaks (\#), relative frequency of occurrence (\%), Normalized Height of the peak (NorH), Maximum Height of the peak (MaxH), azimuth, and standard deviation (sd).

The results of the azimuthal analyses by frequency (upper part of the rose diagram) and by cumulative length (lower part of the rose diagram) are presented in Fig. 4. These results show that both the Marginal and Transitional Zones are characterized by two azimuthal systems while the TSF unit presents a single system.

The Marginal Zone consists of a total of 83 elements. The azimuthal analysis (Fig. 4a) shows three main Gaussian peaks in this unit. These show well-defined preferential orientations: NWSE, which is characterized by two peaks at $\mathrm{N} 14^{\circ} / 17^{\circ} \mathrm{W}$ and $\mathrm{N} 38^{\circ} / 41^{\circ} \mathrm{W}$ and NE-SW, which is characterized by a peak at $\mathrm{N} 55^{\circ} / 56^{\circ} \mathrm{E}$. These main trends identify the two main systems of the Marginal Zone. The NE-SW system occurs within the ASM and SSM and it is called Marginal Zone 1 (MZ1, green color in Fig. 3) and the NW-SE system occurs within the LEM and TEM and it is called Marginal Zone 2 (MZ2, blue color in Fig. 3). The two peaks of the NW-SE system identify a single system with a large standard deviation rather than two conjugate systems

This article is protected by copyright. All rights reserved. 
because the $24^{\circ}$ angle between the peaks is too small to validate the conjugate system hypothesis.

Analyses of the Transitional Zone contain a total of 183 elements. Two preferential Gaussian peaks characterize this unit (Figs. 3, 4b). They are nearly orthogonal to one another and trend $\mathrm{N} 37^{\circ} / 38^{\circ} \mathrm{E}$ and $\mathrm{N} 58^{\circ} / 60^{\circ} \mathrm{W}$. These systems are called Transitional Zone 1 (TZ1, purple color in Fig. 3) and Transitional Zone 2 (TZ2, red color in Fig. 3), respectively. These have similar spatial distribution and are more densely populated near the SSM-TEM and ASM-LEM corners of the Marginal Zone. The analysis by cumulative length shows that TZ1 presents longer structures than TZ2 (Fig. 4b, lowermost diagram).

A total of 88 elements were identified and analyzed within the TSF unit. They define a fifth system that trends $\mathrm{N} 39^{\circ} / 40^{\circ} \mathrm{W}$ (orange color in Figs. 3, 4c). The minor Gaussian peak trending $\mathrm{N} 15^{\circ} / 18^{\circ} \mathrm{W}$ may be attributed to the spatial variability of this system.

\subsection{Lineament domain analysis}

Identification of SPT structure systems was integrated with lineament domain analysis (Wise et al., 1985) to elucidate the tectonic and geodynamic setting of the SPT region.

Images at km scales allowed investigations of evidence for linear topographic features that characterize planetary surfaces.

This work refers to the term "lineaments" as faint and poorly visible straight features that can be used to infer the geodynamic setting of tectonized regions despite the fact that they seldom correspond to known geologic elements (Wise et al., 1985) and, in places, can differ from the structural systems that were recognized by manual mapping (Fig. 3). The mapped systems (MZ1, MZ2, TZ1, TZ2, and TSF systems) represent the brittle evidence of tectonic deformation (i.e., fractures/faults) while the lineaments are thought to follow the surface trajectory of crustal stresses. They do not correspond to a single morphology but instead are a series of well-aligned features that belong to different landforms (Wise et al., 1985).

These characteristics require identification by automatic techniques to avoid detection bias in the detections and to emphasize their rectilinearity (Casas et al., 2000; Hardcastle, 1995; Salvini, 1985; Wise, 1982; Wise et al., 1985).

This article is protected by copyright. All rights reserved. 
Lineaments result from alignments of tonal and morphological features in the topography (e.g. series of valleys and reliefs) and are enhanced by low angle illumination. On Earth, they are influenced by preferential erosion directions related to deformations induced by upper crustal stresses/kinematic conditions (Al Hseinat et al., 2020; Austin \& Blenkinsop, 2008; Cianfarra \& Salvini, 2014; Kudo et al., 2004; Milbury et al., 2007; Oakey, 1994; Rossi et al., 2018; Wise, 1982; Wise et al., 1985). Since few erosive agents are expected on Enceladus' surface, lineaments are already discernible on the surface. They are spatially distributed within a welldefined area affected by tectonic stress and cluster around preferential orientations to form lineament domains that are parallel to the maximum horizontal stress $\left(\mathrm{Sh}_{\max }\right)$ and perpendicular to the minimum horizontal stress ( $\mathrm{Sh}_{\min }$ ) (Pinheiro et al., 2019; Wise et al., 1985). In this way, lineament domains can be used to infer the crustal stresses and kinematics of the upper crust at regional scale (Cianfarra \& Salvini, 2014, 2016b; Lucianetti et al., 2017; Pinheiro et al., 2019; Wise, 1982; Wise et al., 1985).

Two different scales of processes at regional and local scales, respectively, are referred to as dynamic and kinematic processes and are related to their different dimensions compared to the maximum available energy on planetary surfaces. A good example is represented by the kinematics of the San Andreas Fault, which is a regional-scale crustal discontinuity related to relative motions between two plates (i.e., the Juan de Fuca and the North American Plates) and the deformation pattern produced by the stress field which is generated at a more local scale by the kinematic activity of the regional discontinuity (Turcotte \& Schubert, 2014, pp. 118-131; Carreras, 2001; Salvini \& Storti, 2005; Cianfarra \& Maggi, 2017).

In this way, regional kinematic zones are often the product of these two processes. They lead to development of two generations of lineament domains which are the kinematic lineament domain and subordinate dynamic lineament domain. Kinematic lineament domains are relatively longer than the dynamic domains (Rossi et al., 2018).

Integration and comparison of the identified lineament domains with the mapped structures (Fig. 3 ) allowed to characterize the geodynamic meaning of the recognized systems. This analysis enabled identification of the stress field in the SPT region.

We performed an automatic detection of the SPT lineaments on the base mosaic which had been filtered by various methods (smoothing, Laplacian derivative and threshold filters) to enhance the high spatial frequency in the image and investigated features, as well as to remove noise and

This article is protected by copyright. All rights reserved. 
null pixels. SID software (Salvini, 1985) was used to compute a systematic search for all possible straight segments in a digital image of pixel alignments according to a set of parameters which describe the shape of the lineaments to be detected. They are the $\min / \max$ length of the detectable lineaments, number of pixels above a given threshold value, and pixel size of the analyzed image and separation, that is the maximum distance between lineament segments (Rossi et al., 2018). A total of 2993 lineaments were identified within the SPT region (Fig. 5 shows an example of the identified lineaments). These were cumulated for the total data analysis to determine the regional tectonic setting. We performed a polymodal Gaussian fit by frequency and also by cumulative length to infer the azimuthal trends that define lineament domains in the SPT region. The two main peaks of each analysis (red and blue peaks in Fig. 6) identify lineament domains while the others are not relevant since they are related to local scattering. Azimuthal analyses by frequency and cumulative length share the three main Gaussian peaks: NW-SE $\left(\mathrm{N} 39^{\circ} / 41^{\circ} \mathrm{W}\right), \mathrm{NE}-\mathrm{SW}\left(\mathrm{N} 44^{\circ} / 45^{\circ} \mathrm{E}\right)$, and E-W (N86 $\left./ 90^{\circ} \mathrm{E}\right)$. Analysis by frequency recognized a fourth, minor peak trending $\mathrm{N}-\mathrm{S}\left(\mathrm{N} 2^{\circ} \mathrm{W}\right.$; Fig. $\left.6 \mathrm{a}\right)$. The two main peaks (i.e. NW-SE and NE-SW) represent the two main lineament domains in the SPT region.

Lineament azimuthal analyses were also performed separately for each structural unit (i.e., the Marginal Zone, Transitional Zone, and TSF). Both analyses of the Marginal Zone identify two lineament domains trending NW-SE $\left(\mathrm{N} 22^{\circ}-25^{\circ} \mathrm{W}\right)$ and WNW-ESE $\left(\mathrm{N} 80^{\circ}-82^{\circ} \mathrm{W}\right)$ (Fig. 6b). The first domain exhibits a spatial distribution that is relatively more clustered than the second distribution (i.e. the peak is thinner) and is characterized by longer lineaments. Analysis of the lineaments in the Marginal Zone identified a third peak which trended NE-SW.

Lineament analyses within the Transitional Zone recognizes three peaks that identifies two main lineament domains. These trend NE-SW (N30 $\left.{ }^{\circ}-31^{\circ} \mathrm{E}\right)$ and NW-SE (N39 $-45^{\circ} \mathrm{W} ; \mathrm{Fig}$. 6c). The NE-SW and NW-SE lineament domains in the Transitional Zone are similar to the azimuthal trends obtained from the analyses of the TZ1 and TZ2 systems (Fig. 4b) and exhibit higher standard deviation (sd). The azimuthal analysis by cumulative length of the N-S Gaussian peak shows lineaments which are shorter than the other two (Fig. 6c, lower half of the rose diagram). Within the TSF, a lineament domain occurs with a N10 $/ 8^{\circ} \mathrm{W}$ trend (Fig. 6d). Lineament azimuthal analyses enabled recognition of lineament domains with trend comparable to structural system trends (Fig. 3). The comparison allowed inference of tectonic regimes that affect the SPT region.

This article is protected by copyright. All rights reserved. 


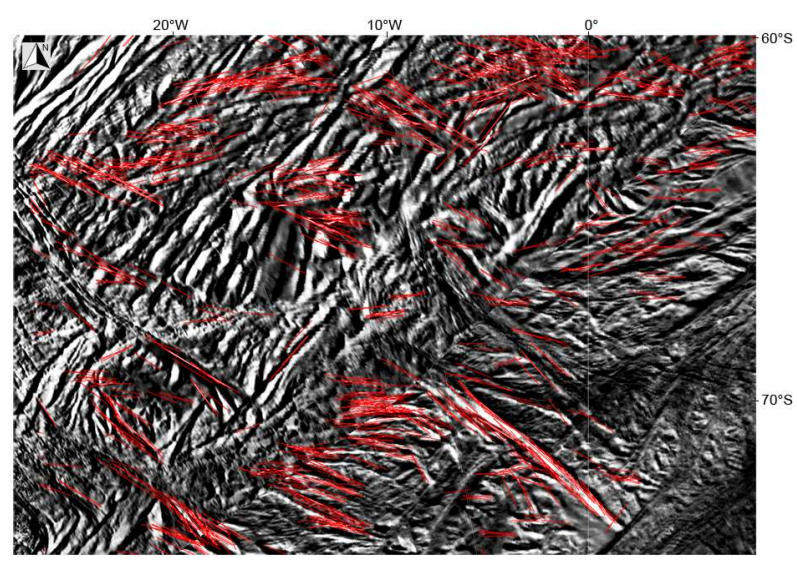

Figure 5. Example of detected lineaments (red lines). This is a subset of the SPT region and its location is shown in Fig. 1.

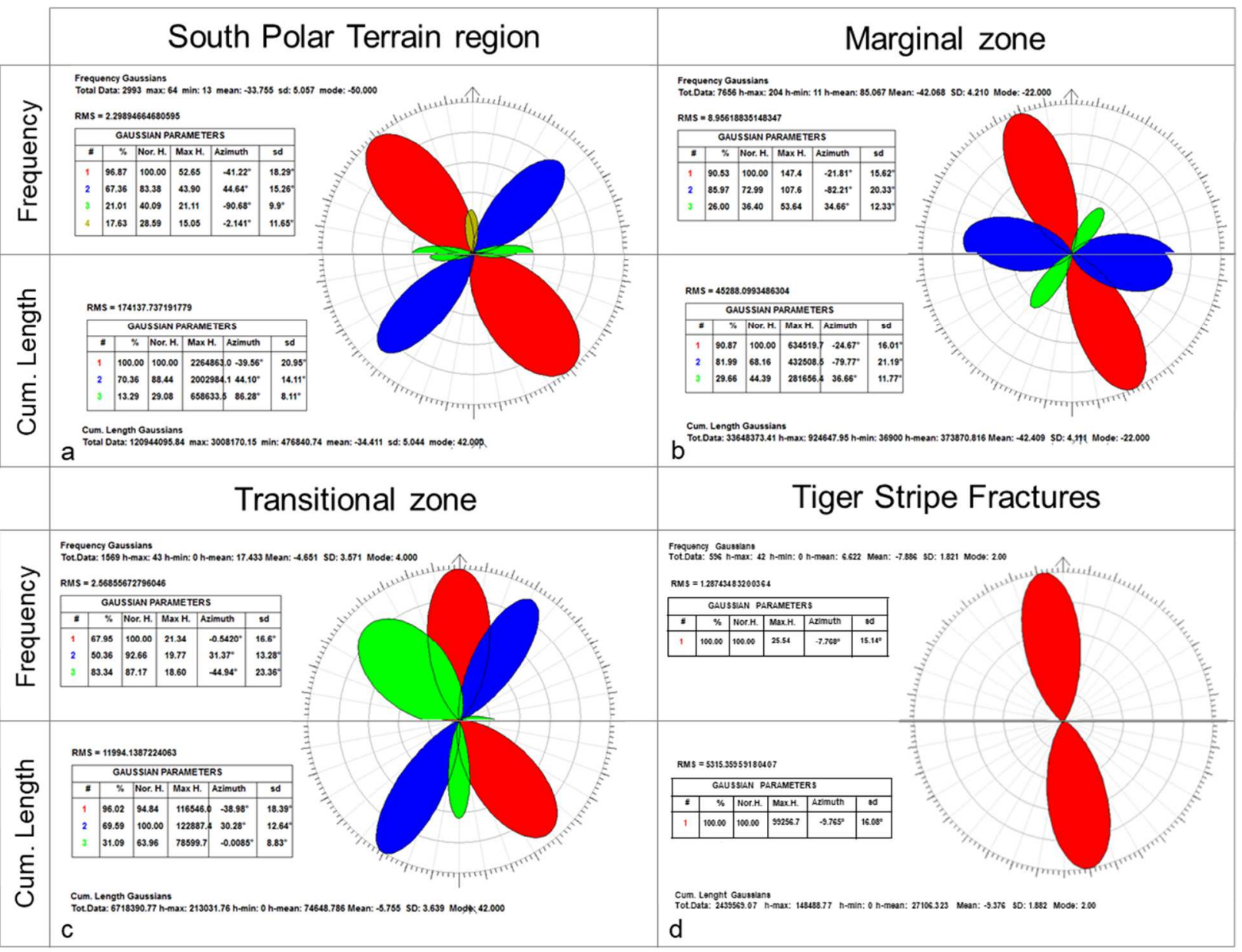

This article is protected by copyright. All rights reserved. 
Figure 6. Azimuthal analyses of the lineaments identified in the SPT systems. The wind rose diagrams are subdivided into two semicircles which show analyses by frequency (uppermost diagram) and analyses by cumulative length (lowermost diagram). Analyses of the a) SPT region, b) Marginal Zone, c) Transitional Zone, and d) TSF. The Gaussian Parameters are reported in Fig. 4.

\subsection{Length/Spacing analysis}

The Length/Spacing ratio $(\mathrm{L} / \mathrm{S})$ is a non-dimensional parameter that characterizes the brittle structure intensity of a crust/layer (i.e. brittle deformation produced by the cumulative activity of tectonic stresses) which is independent from the scale of observation (Cianfarra \& Salvini 2016a; Durney \& Kisch, 1994; Rossi et al., 2018; Salvini, 2013; Tavani et al., 2006). The measured values for computing this parameter are the length of each structure (L) and its spacing (S) with respect to the adjacent and nearly parallel structure of the same system. This ratio quantitatively reflects the "fracture infilling process" which is related to which new faults or fractures nucleate between pairs of pre-existing faults or fractures during progressive brittle deformation (Bai \& Pollard, 2000a, 2000b; Lachenbruch, 1961; Salvini, 2013). We considered a crustal block with dimension $\mathrm{L}$ by $\mathrm{S}$ and thickness $\mathrm{H}$. The stress (Pc) required to split the block along a new $\mathrm{L}$ by $\mathrm{H}$ fracture results from the stress $(\mathrm{P})$ exerted through the $\mathrm{S}$ by $\mathrm{H}$ surface and by considering the contribution from the underlying ocean to be negligible. An equation is easily derived (i.e., $\mathrm{Pc} \cdot \mathrm{L} \cdot \mathrm{H}=a \cdot \mathrm{P} \cdot \mathrm{S} \cdot \mathrm{H}$, where $a$ represents the proportional coefficient) which shows that the ratio $\mathrm{L} / \mathrm{S}$ is related to the quantitative relationship between the outer stress $(\mathrm{P})$ and block material strength (Pc). This relationship is valid for any brittle material including the ice of planetary bodies. The L/S ratio thus constitutes a proxy for the amount of cumulative brittle deformation in a region and in turn is related to the cumulative intensity of the applied stresses (Rossi et al., 2018; Salvini, 2013). In this study, the L/S ratio was computed to infer the morphotectonic pattern of the various tectonic regimes (e.g. Fossen, 2010). We assumed that the L/S ratio was initially relatively homogeneous in the studied region and this assumption was based on a relatively constant thickness, $\mathrm{H}$, and the rheology of the analyzed crust. By following this, any variation in this ratio would result from the deformation produced by successive (i.e. after rupture) tectonic processes. Indeed, for a given thickness of a deformed region and a given amount of cumulative deformation, the L/S parameter in extensional tectonic conditions differs from the compressional tectonic conditions (Fossen, 2010; Woodward et al., 1989). The latter are believed to exhibit a

This article is protected by copyright. All rights reserved. 
shorter periodicity (i.e. the L/S parameter) of their morphotectonic structures for the induced shortening as opposed to the longer periodicity which results from the extensional activity of normal faults (Fossen, 2010). In this way, closer structures (relatively high L/S) are often observed in compressional regimes and the opposite trend characterizes extensional regimes (Woodward et al., 1989). For instance: a series of ten normal faults $\left(\operatorname{dip}=60^{\circ}\right)$ with horizontal length of $10000 \mathrm{~m}$, spaced at $1000 \mathrm{~m}$, and with throw of $100 \mathrm{~m}$ will produce a relative distance of $150 \mathrm{~m}$ and final extension of $15000 \mathrm{~m}$. From an initial L/S value of 10 at the failure instant (that is, no significant displacement, the throw along the faults will decrease the L/S parameter to 8. On the other hand, a series of ten inverse faults (dip $\left.=30^{\circ}\right), 10000 \mathrm{~m} \mathrm{long}$, spaced at $1000 \mathrm{~m}$ and with throw of $100 \mathrm{~m}$ will have an initial L/S value of 10 (prior to displacement) and will produce a relative fault approaching of $86 \mathrm{~m}$ and final shortening of $9140 \mathrm{~m}$. In the latter case, after the displacement, the L/S value will increase to 10.9 .

L/S mean value and frequency were computed for the five tectonic systems identified in the SPT within a significant range of 0 to 10 to avoid biases induced by the few outliers and their relative histograms were normalized to a scale of 0 to 100 with respect to their mode to allow comparison between the systems (Rossi et al., 2018). The analyses of the TZ1 and TZ2 systems provided the only comparable results which occupy the same area and their mean values (obtained from the mean of the L/S measured for each couple of data, i.e. 72 and 47 data for TZ1 and TZ2, respectively) provided a consistent difference. The TZ1 system shows a mean L/S value of 9.9 (Fig. 7a) which is higher than the mean TZ2 L/S value of 3.5 (Fig. 7b). In this way, their analyses indicate two relatively different tectonic contexts (Fig. 7).

This article is protected by copyright. All rights reserved. 

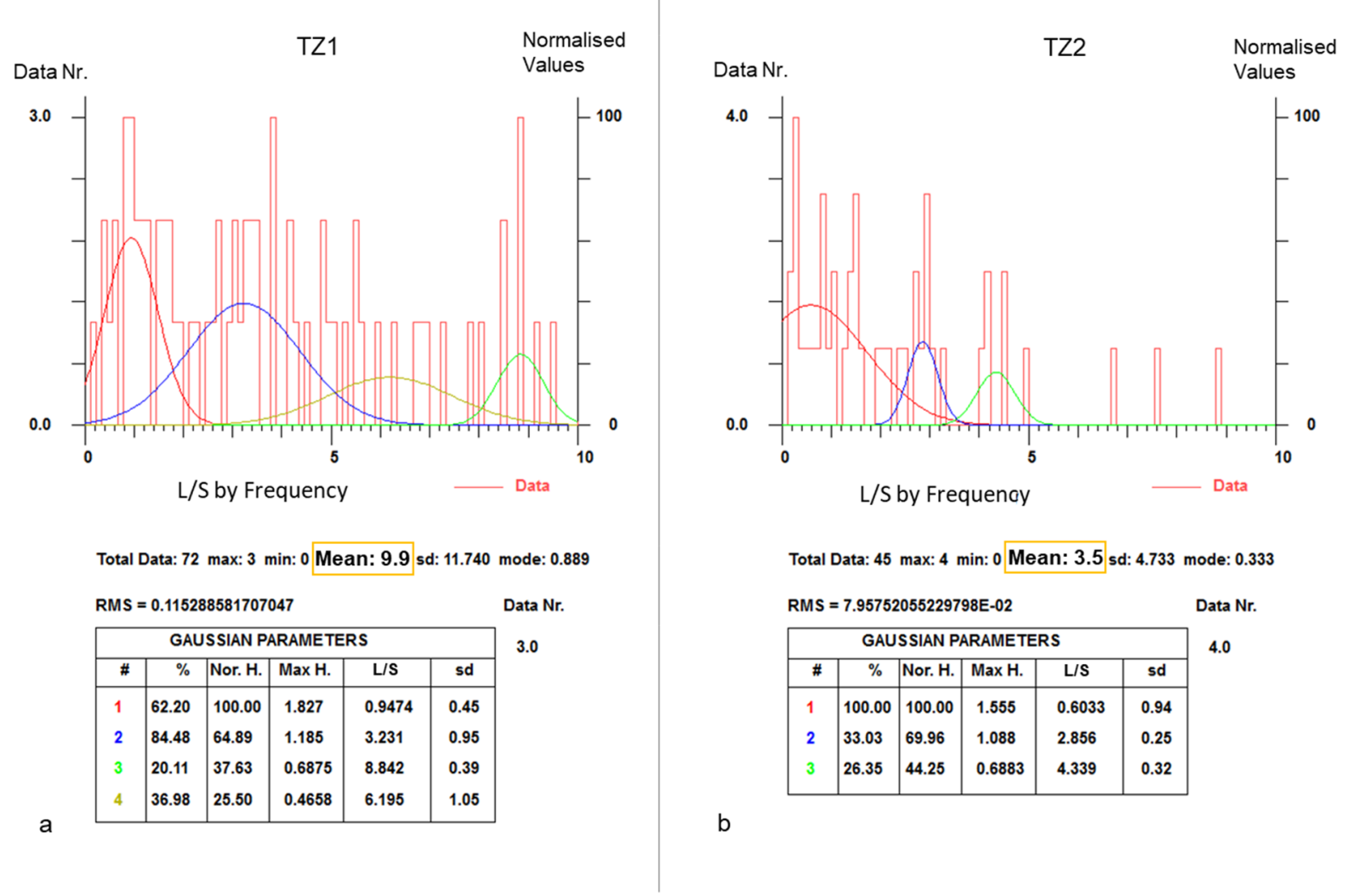

Figure 7. Length/Spacing analysis of the Transitional Zone. A total of four Gaussians (red, blue, green, and yellow) represent the spatial frequency of the Transitional Zone structures. a) the TZ1 $\mathrm{L} / \mathrm{S}$ analysis shows a mean periodicity of 9.9 and including also data out of the histogram range (orange square) and b) the TZ2 L/S analysis shows a mean periodicity of 3.5 (orange square). The max values refer to the maximum no. of measures within a histogram interval (i.e. frequency).

\subsection{Texture identification}

The base mosaic includes ISS (wide and narrow angle cameras) single-band images (greyscale) whose pixel DNs are related to the energy reflected by the surface toward the sensor in the 0.35 $1.10 \mu \mathrm{m}$ interval (Knowles, 2016). The texture (i.e. regularly spaced tonal variations in an image; Fern \& Warner, 2002) of the mosaic image is characterized by regions with characteristic and nearly homogeneous periodicity of grey tones (Fig. 8). This periodicity is related to the different tectonic/morphologic/compositional history of each region. Extensional tectonics generally tend to generate sets of brittle deformation structures (e.g., faults, extensional fractures, and lineaments) that, with the persistence of extensional tectonics through time, tend to step away from each other and result in increasing texture wavelength. On the other hand, in compressional

This article is protected by copyright. All rights reserved. 
regimes, the same elements tend to move closer to each other as an effect of the general shortening associated with the persistence of deformation. This assumption is considered for a given thickness of deformed region and given amount of deformation. In this way, relatively shorter texture wavelengths (i.e. higher periodicity) may indicate the presence of sectors affected by compressional regimes and longer texture wavelengths may be associated with sectors which have been subjected to extension.
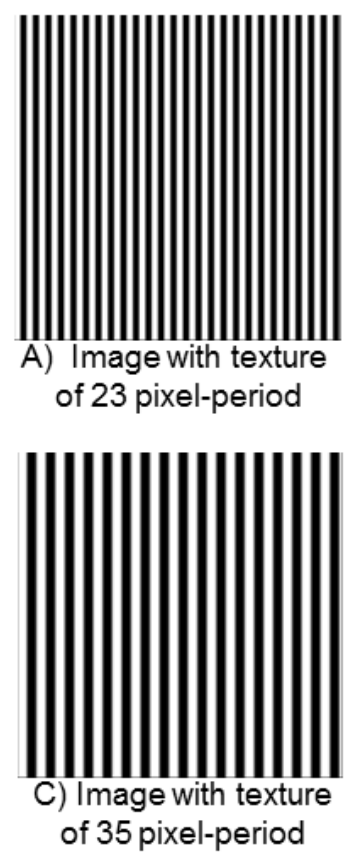
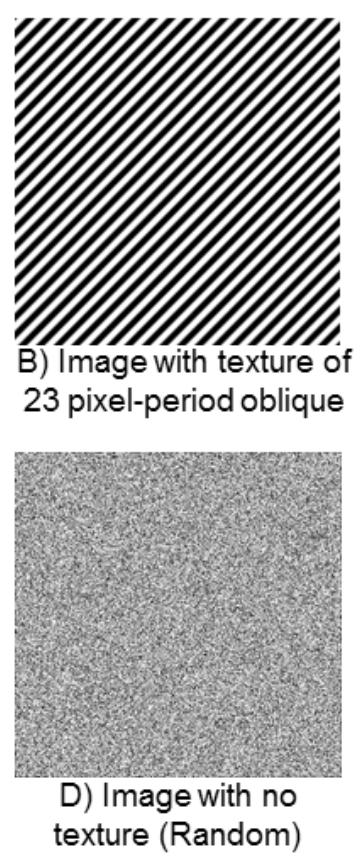

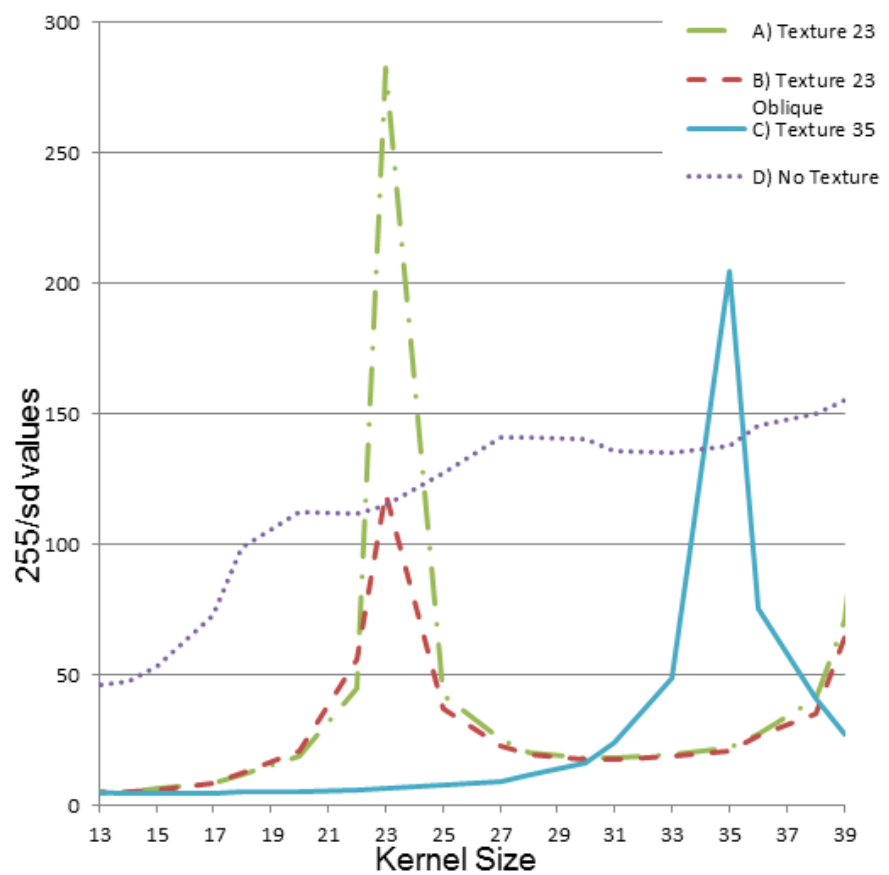

Figure 8. Example of standard deviation (sd) analysis for various kernels on a periodic textured image. To aid visualization, the values are expressed as $255 /$ sd values. In this way, the presence of a periodic texture is indicated by a peak in the histogram.

In image-processing applications, digital techniques (i.e. filters) allow to reveal spatial information of an image and aid identification of its characteristic texture. We prepared subsets of key areas of the SPT (shown in Rossi 2020) to find the optimal filtering kernels to characterize regions with extensional or compressional tectonics. Based on this procedure, image

This article is protected by copyright. All rights reserved. 
texture was analyzed by comparing a series of convolution low-pass filters to identify the characteristic textural wavelength in the SPT. The presence of a characteristic wavelength was identified by a minimum value of the standard deviation by increasing the kernel dimension. A decrease in the standard deviation (sd) value reveals the presence of a texture wavelength that correspond to the kernel size used in that filter. An example is shown in Fig. 8 and demonstrates the results of this processing applied to synthetic images with texture periodicity of 23 pixels both along the $\mathrm{x}$-axis (A) and oblique (B) and 35 pixels (C). These wavelengths were added to a (sub-ordered) 10\% random scattered original image. The fourth image (D in Fig. 8) corresponds to fully random DN values (i.e. no texture is present). The derived 255/sd parameter was used to show the presence of a periodic texture as a peak (maximum) in the histogram. Please note that no maxima are present in the untextured image (D). The texture wavelength in the image corresponds to the first maximum value of the 255/sd parameter and the corresponding filter kernel has the same dimension as the texture wavelength. This process was applied to key subsets of the SPT where extensional or compressional regimes are expected. A series of inhouse prepared routines were applied to identify optimal filter kernels and characteristic texture wavelengths for these areas. We repeated the filtering up to a kernel size of $59 \times 59$ pixels and 59 x 59 pixels for the standard deviation (sd) of the filtered image. This procedure enabled identification of the preferential tectonic regimes in the key subsets. The key subset corresponding to extensional regimes is characterized by a minimum sd value for the low-pass 51 x 51 kernel filtered image and a similar minimum is observed in the $23 \times 23$ kernel-filtered image in the key area which corresponding to a compressional regime. The identified filters (i.e. $51 \times 51,23 \times 23$, and $51 \times 51 \mathrm{sd}$ ) were applied to the SPT image mosaic and a total of three filtered images of the SPT region were obtained. These were in turn combined into RGB bands to obtain a synthetic image. The $51 \times 51$ kernel filtered image was used for the red band, the $23 \times 23$ kernel filtered image was used for the green band, and the 51x51 kernel filtered sd was used for the blue band. The classified image produced was then converted to HSL to add the reference morphology (i.e. the original image) in the L band. The final output image was obtained by reconversion to RGB. This result is shown in Fig. 9 in which the SPT region is characterized by high- (blue color) and low- (yellow color) frequency zones and intermediate zones (cyan and magenta colors). The SSM-TEM and ASM-LEM corners are characterized by higher-frequency pixel texture (blue) while the SSM-LEM and ASM-TEM corners present lower-frequency pixel

This article is protected by copyright. All rights reserved. 
texture (yellow). These results are indicative of different morphological/structural periodicity within the SPT region.

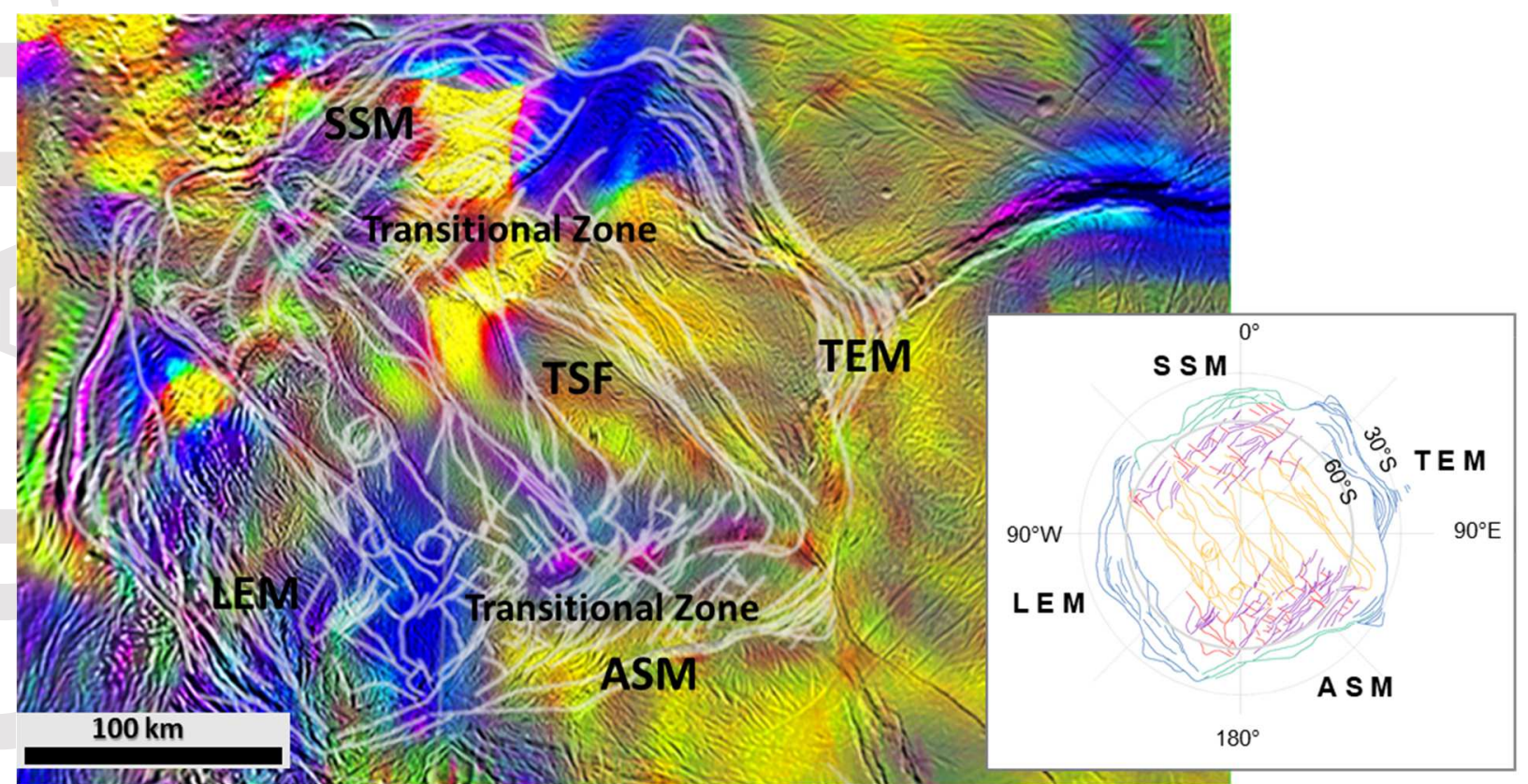

Figure 9. Final converted red green blue color (RGB) synthetic image with reference morphology. The blue color refers to high-frequency, compressional structures and yellow color refers to low-frequency, extensional structures. On the right, the reference structural map (Fig. 3) is shown. The white lines represent the mapped structures of the reference structural map (Fig. 3) shown on the right.

\section{Discussion}

The SPT region of Enceladus is composed of three main structural units, i.e. the Marginal Zone, Transitional Zone and Tiger Stripe Fractures which are all characterized by the presence of brittle deformation. Structural mapping followed by quantitative analyses of the azimuth, spatial distribution and frequency of the recognized structures enabled identification of five tectonic systems in the structural units. These are the MZ1 and MZ2 systems within the Marginal Zone, TZ1 and TZ2 systems within the Transitional Zone, and TSF system (Fig. 3). Lineament domain 
analyses enabled inference of the stress field responsible for the formation of each system and to propose a tectonic model for the SPT.

\subsection{Lineament domain interpretation}

The lineament domain analysis performed in the SPT region shows two domains which are oriented approximately $90^{\circ}$ to each other (Fig. 6a). These are the NW-SE domain (i.e. the red peak in Fig. 6a) and the NE-SW domain (i.e. the blue peak in Fig. 6a) and result from two opposite kinematic regimes.

According to Pinheiro et al. (2019) the main NW-SE lineament domain is parallel to the maximum horizontal stress $\left(\mathrm{Sh}_{\max }\right)$ and is orthogonal to the minimum horizontal stress $\left(\mathrm{Sh}_{\min }\right)$ and indicates transtensional structures which are compatible with E-W right-lateral kinematics.

On the other hand, the opposite trend of the second NE-SW lineament domain is compatible with left-lateral kinematics. In this manner, the main NW-SE lineament domain is produced by regional right-lateral kinematics which in turn induces smaller-scale left-lateral kinematics which are responsible for the development of the secondary lineament domain ( NE-SW) that is compatible with the TSF displacement.

The results obtained confirm that the TSF cuts and offsets the other structures and ancient Tiger Stripes with sinistral displacements (Patthoff \& Kattenhorn, 2011). Their horsetail geometry termination assumes an S-shape which is derived from dragging of the regional right-lateral kinematics along the SSM and ASM (as is also observed by Yin \& Pappalardo, 2015). The $\mathrm{N} 10^{\circ} / 8^{\circ} \mathrm{W}$ trend of the lineament domain within the TSF area is compatible with this regional right-lateral shear (Fig. 6d).

The Marginal Zone shows symmetrical similarities. The systems of the LEM and TEM edges are more sinuous than those of the SSM and ASM edges and suggest a variability of tectonic regimes within the Marginal Zone. The lineament domains recognized within the Marginal Zone (Fig. 6b) represent kinematic domains which are consistent with regional right-lateral strike-slip. Their $\mathrm{N} 22^{\circ} \mathrm{W}$ and $\mathrm{N} 82^{\circ} \mathrm{W}$ trends are compatible with the MZ2 system and constitute domains that are synthetic and antithetic to the regional shear. On the other hand, the MZ1 system indicates the nearly pure right-lateral strike-slip structures that form the SSM and ASM edges. The lineament domains within the Transitional Zone characterize well-defined tectonic regimes with similar significance. The nearly orthogonal NW-SE and NE-SW lineament domains

This article is protected by copyright. All rights reserved. 
(N39 $/ 45^{\circ} \mathrm{W}$ and $\mathrm{N} 30^{\circ} / 32^{\circ} \mathrm{E}$, respectively; Fig. 6c) present shorter lineaments than those recognized in the Marginal Zone and exhibit similar trend to the TZ1 and the TZ2 systems (Fig. $4 b$ ). These are dynamic lineament domains produced by relative movement directions (Rossi et al., 2018). They are the result of the internal stress field induced by regional right-lateral shear. In this manner, the lineament domain setting of the Transitional Zone represents the subsidiary tectonic regimes that are associated with the SSM and ASM regional right-lateral strike-slip. These kinematics are produced by the SPT horizontal stresses, namely $\mathrm{Sh}_{\max }$ and $\mathrm{Sh}_{\min }$, that are NW-SE and NE-SW oriented, respectively. These develop the dynamic lineament domains associated with the TZ1 and TZ2 systems. In this manner, compression is expected to produce the NE-SW lineament domain, which is related to TZ1, and extension is expected to develop the NW-SE lineament domain, which is related to TZ2. The difference in sd values, which are related to their spatial distribution, of these lineament domains shows that the NW-SE lineaments are more scattered than the NE-SW lineaments (Fig. 6c).

\subsection{Length/Spacing interpretation}

The difference between TZ1 and TZ2 is confirmed by their L/S values (Fig. 7). As mentioned previously, closely spaced structures are often observed in compressional regimes (thrust faults, imbricate geometries, and folds) where horizontal shortening occurs and in turn the spacing among structures decreases (Bai \& Pollard, 2000a, 2000b; Fossen, 2010; Lachenbruch, 1961; Lianchong et al., 2014; Woodward et al., 1989). In this manner, the TZ1 and TZ2 systems are characterized by stress-related structures which are associated with dip-slip tectonics. The higher TZ1 L/S value (9.9, Fig. 7a) is consistent with compressional tectonics while the smaller L/S value of TZ2 (3.5, Fig. 7b) is consistent with extensional tectonics.

\subsection{Image processing interpretation}

The image processing results show that various morphological periodicities occur within the SPT region and confirm the coexistence of several tectonic regimes. Fig. 9 allows recognition of clusters with relatively higher- and lower-frequency pixel texture that in turn identify short and long morphological periodicity, respectively. These texture clusters are enhanced at the corners of the Marginal Zone (Fig. 9). The SSM-TEM and ASM-LEM corners exhibit shorter periodicity than the SSM-LEM and ASM-TEM periodicity. The compressional shortened regions are

This article is protected by copyright. All rights reserved. 
characterized by closely spaced structures. Conversely, extensional regime regions are characterized by longer structural periodicity (i.e. greater spacing between structures). This indicates that the corners of the Marginal Zone show symmetrical contraposition of deformation styles. A prevalence of compression occurs within the SSM-TEM and ASM-LEM corners (blue color in Fig. 9) and a prevalence of extension occurs within the SSM-LEM and ASM-TEM corners (yellow color in Fig. 9). The RGB synthetic image in Fig. 9 shows in a color-coded way the possible compressional and extensional zones (blue and yellow, respectively) and possible transpressional and transtensional zones (cyan and magenta, respectively).

\subsection{Geometric setting}

Regional kinematics affect the SPT region by developing the SSM and ASM strike-slip and internal structures whose geometrical relationships are essential for understanding the responsible process.

The TSF form a mean angle of $75^{\circ}$ with the SSM and ASM edges that represent the boundaries of the right-lateral strike-slip corridor. In particular, it is assumed that at their formation, the internal structure, i.e. the TSF, developed at approximately $45^{\circ}$ with respect to the SSM and ASM. According to Cianfarra and Salvini (2015), a pure strike-slip regime setting is expected to form internal structures at $45^{\circ}$ angles relative to the shear zone boundaries. This angle increases in transpressional regimes and decreases in extensional regimes. In this way, the current value of $75^{\circ}$ indicates an angle which has increased through time that will lead to a maximum angle of approximately $90^{\circ}$ (Cianfarra \& Salvini, 2015). This latter interpretation suggests that the TSF underwent a clockwise rotation of approximately $30^{\circ}$ (from $45^{\circ}$ to $75^{\circ}$ ). The structures interpreted as ancient Tiger Stripes (Patthoff \& Kattenhorn, 2011) form an angle of approximately $40^{\circ}$ with the TSF and exhibit an internal angle with the SSM and ASM of approximately $115^{\circ}$. These ancient Tiger Stripes could have originally formed in a manner analogous to the present-day TSF. They may have formed at $45^{\circ}$ and when they reached the maximum internal angle $\left(90^{\circ}\right)$, became relict Tiger Stripes and passively followed the clockwise rotation with the development of the present-day TSF. This explains the angle exceeding $90^{\circ}$ in the ancient Tiger Stripes. The $30^{\circ}$ rotation of the TSF induced a left-lateral displacement of the ancient Tiger Stripes of approximately $23 \mathrm{~km}$. In a predictive way and by assuming a constant TSF rotation, we can infer that the total offset of the ancient Tiger Stripes would be

This article is protected by copyright. All rights reserved. 
approximately $70 \mathrm{~km}$ when the present-day TSF rotation would stop by reaching the internal angle of approximately $90^{\circ}$.

An alternative hypothesis may explain the origin of the SPT structures. According to Cianfarra and Salvini (2015), the increased internal angle may have resulted from a transpressional regime within the SPT. The presence of folded funiscular plains (Barr \& Preuss, 2010; Nahm \& Kattenohrn, 2015; Spencer \& Nimmo, 2013) may confirm the prevalence of a compressional component in those blocks delimited by the TSF. The texture clusters shown in Fig. 9 within these blocks show compressional and extensional zones. These conditions may represent a transition of the strike-slip motion from transpression to transtension.

We assume that both processes coexist, i.e. rotation and transpression, and in the following, we suggest the block rotation tectonic model that frames the recognized regimes and is consistent with the derived kinematics.

\subsection{Block rotation model for the South Polar Terrain and its possible cause}

The results obtained enable interpreting the tectonics of the SPT region in the framework of the block rotation model (McKenzie \& Jackson, 1986). Fig. 10 shows the proposed model in which regional scale right-lateral strike-slip characterizes the SSM and ASM edges. These regional kinematics are responsible for the development of internal stress conditions that produces a total of four blocks delimited by the TSF. The left-lateral kinematics with a transpressional component between the TSF induces clockwise rotation of the blocks (up to $30^{\circ}$ ). This block rotation generates symmetrical tectonic regimes at opposite vertices of the Marginal Zone: compression occurs within the SSM-TEM and ASM-LEM corners while extension occurs within the SSM-LEM and ASM-TEM corners. The LEM and TEM edges represent transitions in strikeslip regimes from transpression to transtension. The regional kinematics coupled with block rotation are responsible for the formation of the subsidiary TZ1 and TZ2 structures.

This article is protected by copyright. All rights reserved. 


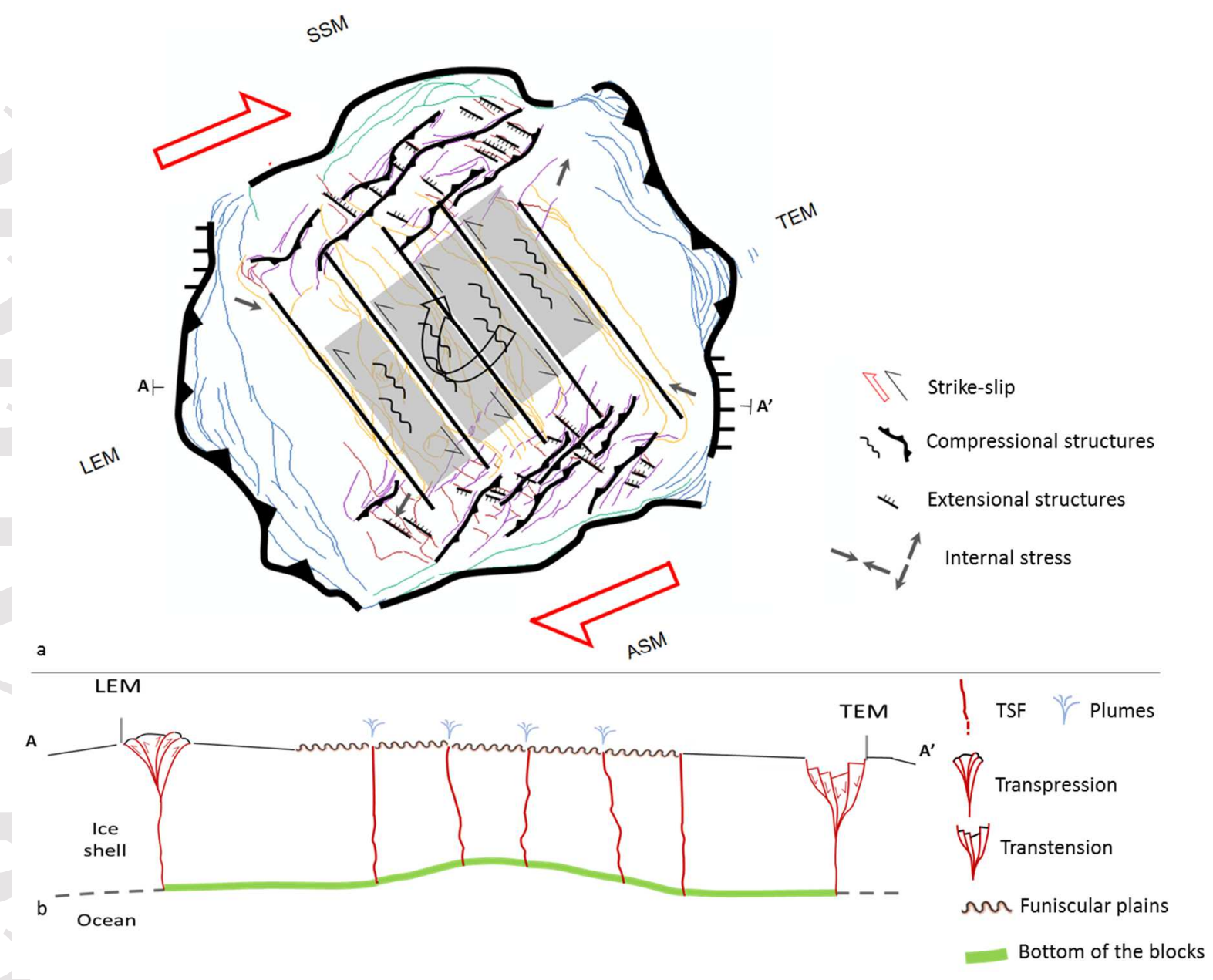

Figure 10. Block rotation tectonic model. a) Map view. The TSF are left-lateral strike-slip faults that delimit four blocks and rotate clockwise (shown by the black curved arrow at the center). The Transitional Zone systems, TZ1 and TZ2, represent compression and extension, respectively. The Marginal Zone MZ1 represents right-lateral strike-slip and MZ2 presents symmetrical and opposite transpressional and transtensional regimes. A and A' represent the location of the b) cross-section view. The TSF are nearly vertical strike-slip structures where plumes are ejected. The LEM and TEM Marginal Zone edges are under transpression and transtension (i.e. positive and negative flowers, respectively).

We propose an evolutionary kinematic model which is shown in Fig. 11. The SPT region is characterized by rigid blocks (Fig. 11a) which are delimited at the SSM and ASM by right-lateral strike-slip structures (Fig. 11b). The kinematics produce internal deformation which is manifested by TSF formation at approximately $45^{\circ}$ which delimit the four blocks (Fig. 11c). The SSM and ASM regional right-lateral strike-slip regimes produce the block rotation of $45^{\circ}+\phi$ and also the subsequent formation of subsidiary structures in the interior (Fig. 11d). Rotation continues until the maximum angle of $90^{\circ}$ is reached (i.e. $\phi=45^{\circ}$, Fig. 11e). Through time, the

This article is protected by copyright. All rights reserved. 
protraction of the regional right-lateral strike-slip will form a second-generation TSF at $45^{\circ}$ (i.e. the current TSF; Fig. 11f). The rotation of the newly formed TSF causes an offset of the ancient TSF of $23 \mathrm{~km}$ in the present-day configuration (Fig. 11g). By considering a constant block rotation process, the future setting of the TSF will offset the ancient ones of $70 \mathrm{~km}$ when they end their rotation by reaching the maximum angle of $90^{\circ}$ (Fig. 11h). This model may repeat until the regional right-lateral tectonics cease.

The kinematics of the SPT structures resulted from external forces responsible for starting tectonic activity. The block rotation model in the SPT is produced by significant shear. The lateral (strike-slip) fault motion may have been driven by tidal stresses that represent differential forces responsible for the deformation of Enceladus' icy crust (e.g. Nimmo et al., 2007; Rhoden et al., 2020). In addition, evidence of polar wander is identified by Tajeddine et al. (2017) and supports the strong presence of the strike-slip displacement suggested by the block rotation model. In this way, both processes can lead to the SPT deformation and induce a thermal anomaly or crustal thickness variations such as its thinning in extensional regions and conversely, its thickening in compressional regions.

\subsection{Comparison with pre-existing models}

The proposed model is partially pertinent with the model of Yin and Pappalardo (2015) (Fig. 2). Both models are based on regional kinematics that affect the SPT region and show that the SSM and ASM edges of the Marginal Zone are dominated by strike-slip motions and that the LEM and TEM edges are affected by a prevalent dip-slip component. Also, both models assume that the TSF are left-lateral strike-slip faults that rotate clockwise.

However, the model proposed by Yin and Pappalardo (2015) and the block rotation model differ in their regional mechanical process. Yin and Pappalardo (2015) suggest flow-like tectonics across the region with the presence of a detachment below the SPT that unifies the LEM and TEM edges from extension to compression, respectively (Fig. 2). Kinematics develop in the leftand right-lateral strike-slip regimes along the SSM and ASM edges, respectively. This process is produced by a thermal event which allows release of gravitational potential energy via lateral viscous flow. This leads to internal formation of left-lateral bookshelf faulting along the TSF and their clockwise rotation which accommodates regional shear.

This article is protected by copyright. All rights reserved. 
In this manner, this model and the block rotation model differ in several key factors, namely: i) the deep crustal development of the Tiger Stripe Fractures; ii) kinematics of the LEM, TEM, and SSM boundaries; iii) evolution of the structures and the SPT region.

i) The development at depth of the TSF is confined to the upper portion of the icy crust in the Yin and Pappalardo (2015) model while the TSF reach the bottom of the icy crust in the block rotation model.

ii) The block rotation model shows a transition in LEM and TEM kinematics from parts under transtension to parts under transpression along the same margin which contrasts with the extensional LEM and compressional TEM in the flow-like tectonic model. In addition, block rotation tectonics produce a right-lateral shear corridor while in flow-like tectonics, the SSM edge is interpreted as left-lateral strike-slip;

iii) The flow-like tectonic model leaves undefined the relationship between TSF and the Marginal Zone structure and the TSF left-lateral kinematics are not easily justified by a potential gravitational process from the LEM to TEM edges. Furthermore, the flow-like tectonics weakly frame the main role of TSF in the SPT region. Their significance as primary structures is framed in the block rotation model in which the TSF play a fundamental role in the deformation of the SPT and their development is responsible for the derived secondary tectonics. The model proposed in this study suggests the importance of regional kinematics that produce the internal clockwise rotation of the blocks which are delimited by the left-lateral TSF. Block-rotation tectonics justify the observed higher permeability along the TSF and clarify the role of the ancient TSF. The absence of an impediment, such as the possible detachment suggested by the flow-like tectonics, favors fluid propagation toward the surface along the TSF that represent preferential upwelling paths. Their kinematics and attitude to reach the bottom of the icy crust, and potentially the subsurface ocean, better explain the activity of the jets along their track.

This article is protected by copyright. All rights reserved. 


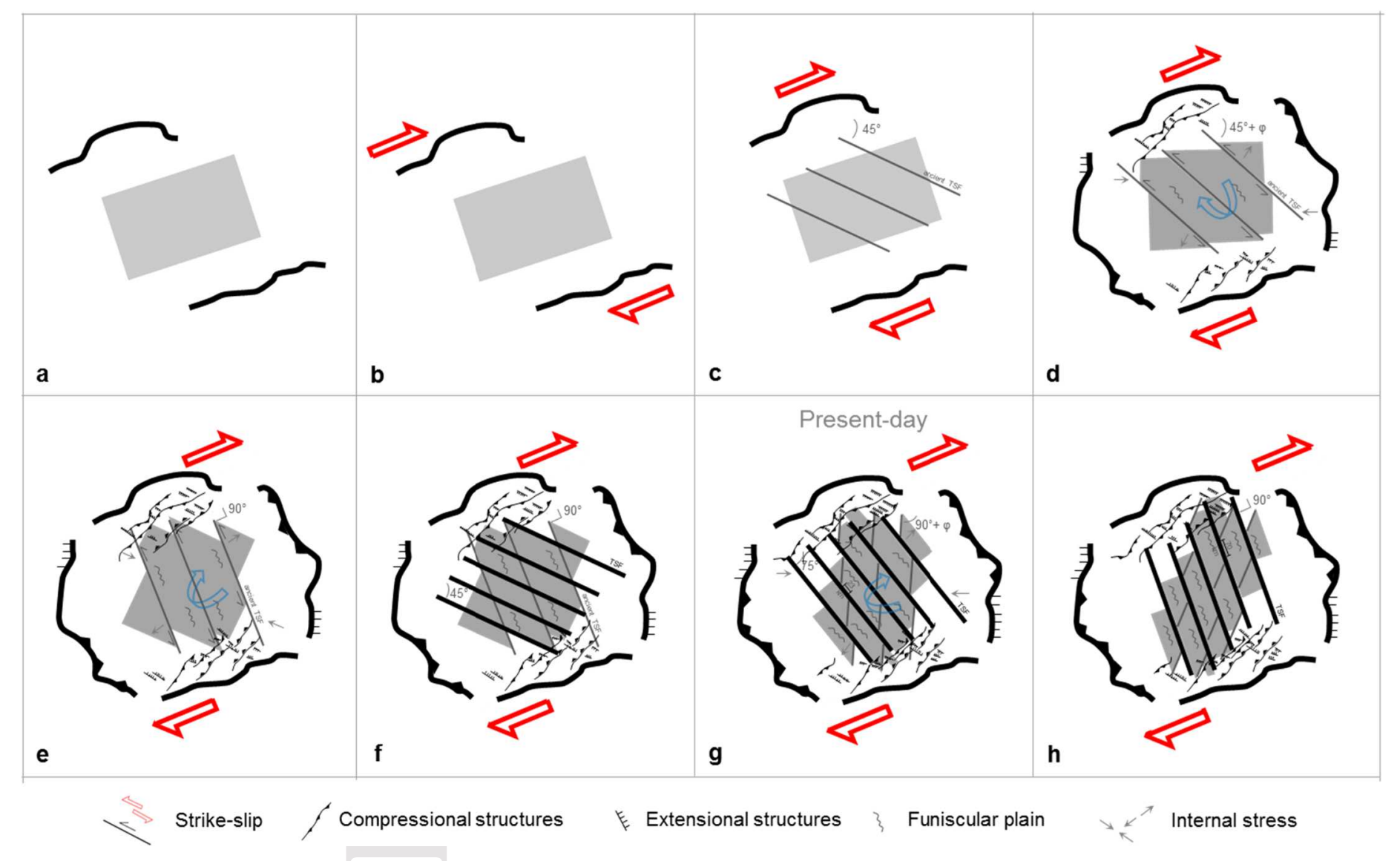

Figure 11. Evolutionary tectonic model of the SPT: a) the SPT is characterized by rigid blocks; b) development of the regional right-lateral kinematics along the SSM and ASM edges; c) development of the TSF (dark-grey lines) at $45^{\circ}$ with the SSM and ASM; d) the left-lateral kinematics of the TSF divides four blocks with a clockwise rotation of $45^{\circ}+\phi$, the TSF and the SSM and ASM strike-slip determine the development of the Transitional Zone structures (TZ1 and TZ2 systems), transpressional component within the blocks (development of the funiscular plains), and transpression and transtension develop along the MZ1 and MZ2 edges; e) end of the TSF clockwise rotation until $90^{\circ}$; f) new generation TSF (black lines) form at $45^{\circ}$; g) the new generation TSF reach the present-day configuration of $75^{\circ}$ by offsetting of $23 \mathrm{~km}$ the ancient TSF that exceed the $90^{\circ}$; h) through time the block rotation will lead the TSF until $90^{\circ}$, with the future offset of the ancient TSF of $70 \mathrm{~km}$. 


\section{Conclusions}

The South Polar Terrain on Enceladus exhibits a complex pattern of fractures and faults in structural units. The analyses performed allow to identify and classify these structures into systems.

The results suggest that the SPT is mainly affected by dual strike-slip tectonic regimes that in turn form subordinate and symmetric compressional and extensional zones. The activity of the SPT of Enceladus reveals block rotation tectonics. Regional right-lateral strike-slip structures enclose the left-lateral kinematics along the Tiger Stripes. These delimit rigid blocks that rotate clockwise and may ease plume eruptions. The described kinematics could represent the effect of local plume sources as in the observed hydrothermal activity in the subsurface ocean.

The block rotation tectonic model represents a key tool to understand the past and future evolution of the SPT. At present, the TSF led to a block rotation of $30^{\circ}$ and through time, these persistent kinematics will lead to a future offset of the internal relict Tiger Stripes of approximately $47 \mathrm{~km}$ by assuming a constant rotation.

These results are significant for future exploration of the satellite to identify preferential zones of investigation (i.e. transtensional/extensional zones) to better obtain information of the subsurface ocean of Enceladus.

\section{Acknowledgments}

We appreciate insightful comments by M. Massironi and two anonymous reviewers that helped to improve the manuscript. Funding for this project came from Roma Tre University ( $\mathrm{PhD}$ fellowship and GeoQuTe research funds). This work has been completed as part of the $\mathrm{PhD}$ project of the first author. We thank the Laboratoire de Planétologie et Géodynamique of the University of Nantes for its kind hospitality. G.T. and O.B. acknowledge the financial support from CNES (Centre National d'Etudes Spatiales, France) in the preparation of the ESA JUICE mission. The data presented in this work are available at the Open Science Framework repository (Rossi, 2020). The analysis were performed by means of ESRI ArcGIS software, SID and DAISY3 software (available at http://host.uniroma3.it/progetti/fralab/Downloads/Programs/), and ENVI software.

\section{References}

Al Hseinat, M. A., Al-Rawabdeh, A., Al-Zidaneen, M., Ghanem, H., Al-Taj, M., Diabat, A., \& Atallah, M. (2020). New Insights for Understanding the Structural Deformation Style of the Strike-Slip Regime along the Wadi Shueib and Amman-Hallabat Structures in Jordan Based on

This article is protected by copyright. All rights reserved. 
Remote Sensing Data Analysis. Geosciences, 10(7), 253.

https://doi.org/10.3390/geosciences10070253

Austin, J.R., \& Blenkinsop, T.G (2008). The Cloncurry Lineament: Geophysical and geological evidence for a deep crustal structure in the Eastern Succession of the Mount Isa Inlier.

Precambrian Res., 163, 50-68. https://doi.org/10.1016/j.precamres.2007.08.012

Bai, T., \& Pollard, D. D. (2000a). Fracture spacing in layered rocks: a new explanation based on the stress transition. Journal of Structural Geology, 22(1), 43-57. https://doi.org/10.1016/S01918141(99)00137-6

Bai, T., \& Pollard, D. D. (2000b). Closely spaced fractures in layered rocks: initiation mechanism and propagation kinematics. Journal of Structural Geology, 22(10), 1409-1425. https://doi.org/10.1016/S0191-8141(00)00062-6

Barr, A. C. (2008). Mobile lid convection beneath Enceladus' south polar terrain. Journal of Geophysical Research: Planets, 113, E07009. https://doi.org/10.1029/2008JE003114

Barr, A. C., \& Preuss, L. J. (2010). On the origin of south polar folds on Enceladus. Icarus, 208(1), 499-503. https://doi.org/10.1016/j.icarus.2010.03.038

Beuthe, M. (2016). Crustal control of dissipative ocean tides in Enceladus and other icy moons. Icarus, 280, 278-299. https://doi.org/10.1016/j.icarus.2016.08.009

Bland, M. T., Becker, T. L., Edmundson, K. L., Roatsch, T., Archinal, B. A., Takir, D., et al. (2018). A new Enceladus global control network, image mosaic, and updated pointing kernels from Cassini's 13-year mission. Earth and Space Science, 5, 604- 621. https://doi.org/10.1029/2018EA000399

Brown, R. H., Clark, R. N., Buratti, B. J., Cruikshank, D. P., Barnes, J. W., Mastrapa, R. M., et al. (2006). Composition and physical properties of Enceladus' surface. Science, 311(5766), 14251428. https://doi.org/10.1126/science.1121031

Čadek, O., Souček, O., Běhounková, M., Choblet, G., Tobie, G., \& Hron, J. (2019). Long-term stability of Enceladus' uneven ice shell. Icarus, 319, 476-484.

https://doi.org/10.1016/j.icarus.2018.10.003.

Čadek, O., Tobie, G., Van Hoolst, T., Massé, M., Choblet, G., Lefèvre, A., et al. (2016). Enceladus's internal ocean and ice shell constrained from Cassini gravity, shape, and libration data. Geophysical Research Letters, 43(11), 5653-5660. https://doi.org/10.1002/2016GL068634

Carr, J. R. (1996). Spectral and textural classification of single and multiple band digital images. Computers \& Geosciences, 22(8), 849-865. https://doi.org/10.1016/S00983004(96)00025-8

This article is protected by copyright. All rights reserved. 
Carreras, J., (2001). Zooming on Northern Cap de Creus shear zones. Journal of Structural Geology 23, 1457-1486. https://doi.org/10.1016/S0191-8141(01)00011-6

Casas, A.M., Cortes, A.L., Maestro, A., Soriano, M.A., Riaguas, A., \& Bernal, J.A (2000).

LIDENS: A program for lneament length and density analysis. Comput. Geosci., 26, 1011-1022.

Choblet, G., Tobie, G., Sotin, C., Běhounková, M., Čadek, O., Postberg, F., \& Souček, O. (2017). Powering prolonged hydrothermal activity inside Enceladus. Nature Astronomy, 1(12), 841-847. https://doi.org/10.1038/s41550-017-0289-8

Cianfarra, P., \& Salvini, F. (2014). Ice sheet surface lineaments as nonconventional indicators of East Antarctica bedrock tectonics. Geosphere, 10(6), 1411-1418. https://doi.org/10.1130/GES01074.1

Cianfarra, P., \& Salvini, F. (2015). Lineament domain of regional strike-slip corridor: insight from the Neogene transtensional De Geer transform fault in NW Spitsbergen. Pure Applied Geophysics 172(5), 1185-1201. https://doi.org/10.1007/s00024-014-0869-9.

Cianfarra, P., \& Salvini, F. (2016a). Quantification of fracturing within fault damage zones affecting late Proterozoic carbonates in Svalbard. Rendiconti Lincei 27(1), 229-241. https://doi.org/10.1007/s12210-016-0527-5.

Cianfarra, P., \& Salvini, F. (2016b). Origin of the adventure subglacial trench linked to Cenozoic extension in the East Antarctic Craton. Tectonophysics 670, 30-37. https://doi.org/10.1016/j.tecto.2015.12.011.

Cianfarra, P., \& Maggi, M., (2017). Cenozoic extension along the reactivated Aurora Fault System in the East Antarctic Craton. Tectonophysics, 703, 135-153. https://doi.org/10.1016/j.tecto.2017.02.019

Collins, G. C., \& Goodman, J. C. (2007). Enceladus' south polar sea. Icarus, 189(1), 72-82. https://doi.org/10.1016/j.icarus.2007.01.010.

Combe, J. P., McCord, T. B., Matson, D. L., Johnson, T. V., Davies, A. G., Scipioni, F., \& Tosi, F. (2019). Nature, distribution and origin of CO2 on Enceladus. Icarus, 317, 491-508. https://doi.org/10.1016/j.icarus.2018.08.007

Crow-Willard, E. N., \& Pappalardo, R. T. (2015). Structural mapping of Enceladus and implications for formation of tectonized regions. Journal of Geophysical Research: Planets, 120(5), 928-950. https://doi.org/10.1002/2015JE004818

Durney, D.W., \& Kisch, H.J. (1994). A field classification and intensity scale for first-generation cleavages. Journal of Australian Geology \& Geophysics 15, 257-295.

Fern, C. J., \& Warner, T. A. (2002). Scale and texture in digital image classification. Photogrammetric Engineering \& Remote Sensing, 68(1), 51-63.

This article is protected by copyright. All rights reserved. 
Filacchione, G., D’Aversa, E., Capaccioni, F., Clark, R. N., Cruikshank, D. P., Ciarniello, M., et al. (2016). Saturn's icy satellites investigated by Cassini-VIMS. IV. Daytime temperature maps. Icarus, 271, 292-313. http://dx.doi.org/10.1016/j.icarus.2016.02.019.

Fossen, H. (2010). Structural Geology. Cambridge, UK, Cambridge University Press.

Gioia, G., Chakraborty, P., Marshak, S., \& Kieffer, S. W. (2007). Unified model of tectonics and heat transport in a frigid Enceladus. Proceedings of the National Academy of Sciences, 104(34), 13578-13581. https://doi.org/10.1073/pnas.0706018104.

Hansen, C. J., Esposito, L., Stewart, A. I. F., Colwell, J., Hendrix, A., Pryor, W., et al. (2006). Enceladus' Water Vapor Plume. Science, 311(57669), 1422-1425. https://doi.org/10.1126/science.1121254.

Hardcastle, K.C. (1995). Photolineament factor: A new computer-aided method for remotely sensing the degree to which the bedrock is fractured. Photogramm. Eng. Remote. Sens., 61, 739 747.

Helfenstein, P., \& Porco, C. C. (2015). Enceladus' geysers: relation to geological features. The Astronomical Journal, 150(3), 96. https://doi.org/10.1088/0004-6256/150/3/96.

Helfenstein, P., Thomas, P. C., Veverka, J., Rathbun, J., Perry, J., Turtle, E., et al. (2006). Patterns of fracture and tectonic convergence near the south pole of Enceladus. Lunar Planet. Sci. 37. Abstract 2182.

Helfenstein, P., Denk, T., Giese, B., Ingersoll, A., Johnson, T. V., McEwen, A. S., et al., (2008). Enceladus South Polar Terrain geology: New details from Cassini ISS high resolution imaging. American Geophysical Union (Fall). Abstract.

Hendrix, A. R., Hansen, C. J., \& Holsclaw, G. M. (2010). The ultraviolet reflectance of Enceladus: Implications for surface composition. Icarus, 206(2), 608-617. https://doi.org/10.1016/j.icarus.2009.11.007.

Hemingway, D., Iess, L., Tajeddine, R., \& Tobie, G. (2018), The interior of Enceladus, in Enceladus and the Icy Moons of Saturn, edited by P. M. Schenk, R. N. Clark, C. J. A. Howett, A. J. Verbiscer, and J. Hunter Waite, pp. 57-77, University of Arizona Press, Tucson, doi:10.2458/azuluapress $\backslash 9780816537075$-ch004.

Hsu, H. W., Postberg, F., Sekine, Y., Shibuya, T., Kempf, S., Hora’nyi, M., et al. (2015). Ongoing hydrothermal activities within Enceladus, Nature, 519, 207-210. https://doi.org/10.1038/nature14262.

Iess, L., Stevenson, D. J., Parisi, M., Hemingway, D., Jacobson, R. A., Lunine, J. I., \& Tortora, P. (2014). The gravity field and interior structure of Enceladus. Science, 344(6179), 78-80. https://doi.org/10.1126/science.1250551.

This article is protected by copyright. All rights reserved. 
Johnston, S. A., \& Montési, L. G. (2017). The impact of a pressurized regional sea or global ocean on stresses on Enceladus. Journal of Geophysical Research: Planets, 122(6), 1258-1275. https://doi.org/10.1002/2016JE005217

Knowles, B. (2016). Cassini Imaging Science Subsystem (ISS) Data User's Guide. Cassini Imaging Central Laboratory for Operations (CICLOPS), Space Science Institute.

Kudo, T., Yamamoto, A., Nohara, T., Kinoshita, H., \& Shichi, R. (2004). Variations of gravity anomaly roughness in Chugoku district, Japan: Relationship with distributions of topographic lineaments. Earth Planets Space, 56, 5-8. https://doi.org/10.1186/BF03352505

Lachenbruch, A. H. (1961). Depth and spacing of tension cracks. Journal of Geophysical Research, 66(12), 4273-4292. https://doi.org/10.1029/JZ066i012p04273.

Le Gall, A., Leyrat, C., Janssen, M. A., Choblet, G., Tobie, G., Bourgeois, O., et al. (2017). Thermally anomalous features in the subsurface of Enceladus's south polar terrain. Nature Astronomy, 1(4), 0063. https://doi.org/10.1038/s41550-017-0063.

Lianchong, L., Shaohua L., \& Chun'an, T. (2014). Fracture spacing behavior in layered rocks subjected to different driving forces: a numerical study based on fracture infilling process. Frontiers of earth science 8(4), 472-489. https://doi.org/10.1007/s11707-014-0427-X.

Lucchetti, A., Pozzobon, R., Mazzarini, F., Cremonese, G., \& Massironi, M. (2017). Brittle ice shell thickness of Enceladus from fracture distribution analysis. Icarus, 297, 252-264. https://doi.org/10.1016/j.icarus.2017.07.009.

Lucianetti, G., Cianfarra, P., \& Mazza, R. (2017). Lineament domain analysis to infer groundwater flow paths: Clues from the Pale di San Martino fractured aquifer, Eastern Italian Alps. Geosphere, 13(5), 1729-1746. https://doi.org/10.1130/GES01500.1.

Maggi, M., Cianfarra, P., Salvini, F., \& de Lima, C.C. (2015). Staircase fractures in microbialites and the role of lamination-related mechanical anisotropy: the example of the acquasanta terme travertine deposits (central Italy). Geological Society of America Bullettin, 127(5-6), 879-896. https://doi.org/10.1130/B31163.1.

Martin, E. S. (2016). The distribution and characterization of strike-slip faults on Enceladus. Geophysical Research Letters, 43(6), 2456-2464. https://doi.org/10.1002/2016GL067805.

Matson, D. L., Castillo, J. C., Lunine, J., \& Johnson, T. V. (2007). Enceladus' plume: Compositional evidence for a hot interior. Icarus, 187(2), 569-573. https://doi.org/10.1016/j.icarus.2006.10.016.

Matsuyama, I., \& Nimmo, F. (2008). Tectonic patterns on reoriented and despun planetary bodies. Icarus, 195(1), 459-473. https://doi.org/10.1016/j.icarus.2007.12.003.

This article is protected by copyright. All rights reserved. 
McKenzie, D., \& Jackson, J. (1986). A block model of distributed deformation by faulting. Journal of the Geological Society, 143(2), 349-

353. https://doi.org/10.1144/gsjgs.143.2.0349.

McKinnon, W. B. (2015). Effect of Enceladus's rapid synchronous spin on interpretation of Cassini gravity. Geophysical Research Letters, 42(7), 2137-2143.

https://doi.org/10.1002/2015GL063384.

Milbury, A.E.C., Smrekar, S.E., Raymond, C.A., \& Schubert, G. (2007). Lithospheric structure in the east region of Mars'dichotomy boundary. Planet. Space Sci., 55, 280-288.

https://doi.org/10.1016/j.pss.2006.03.009

Nahm, A. L., \& Kattenhorn, S. A. (2015). A unified nomenclature for tectonic structures on the surface of Enceladus. Icarus, 258, 67-81. https://doi.org/10.1016/j.icarus.2015.06.009.

Nimmo, F., \& Pappalardo, R. T. (2006). Diapir-induced reorientation of Saturn's moon Enceladus. Nature, 441(7093), 614. https://doi.org/10.1038/nature04821.

Nimmo, F., Spencer, J. R., Pappalardo, R. T., \& Mullen, M. E. (2007). Shear heating as the origin of the plumes and heat flux on Enceladus. Nature, 447(7142), 289-291.

https://doi.org/10.1038/nature05783

Olgin, J. G., Smith-Konter, B. R., \& Pappalardo, R. T. (2011). Limits of Enceladus's ice shell thickness from tidally driven tiger stripe shear failure. Geophysical Research Letters, 38, L02201. https://doi.org/10.1029/2010GL044950.

Oakey, G. (1994). A structural fabric defined by topographic lineaments: Correlation with Tertiary deformation of Ellesmere and Axel Heiberg Islands, Canadian Arctic. J. Geophys. Res., 99, 148-227.

Parkinson, C. D., Liang, M. C., Yung, Y. L., \& Kirschivnk, J. L. (2008). Habitability of Enceladus: planetary conditions for life. Origins of Life and Evolution of Biospheres, 38(4), 355369. https://doi.org/10.1007/s11084-008-9135-4.

Patthoff, D.A., \& Kattenhorn, S. (2011). A fracture history on Enceladus provides evidence for a global ocean. Geophysical Research Letter, 38(18). https://doi.org/10.1029/2011GL048387.

Pinheiro, M. R., Cianfarra, P., Villela, F. N. J., \& Salvini, F. (2019). Tectonics of the Northeastern border of the Parana Basin (Southeastern Brazil) revealed by lineaments domain analysis. Journal of South American Earth Sciences, 102231.

https://doi.org/10.1016/j.jsames.2019.102231.

Porco, C., DiNino, D., \& Nimmo, F. (2014). How the geysers, tidal stresses, and thermal emission across the South Polar terrain of Enceladus are related, The Astronomical Journal, 148(3), 45. https://doi.org/10.1088/0004-6256/148/3/45.

This article is protected by copyright. All rights reserved. 
Porco, C.C., Helfenstein, P., Thomas, P.C., Ingersoll, A.P., Wisdom, J., West, R., et al. (2006). Cassini observes the active south pole of Enceladus. Science 311, 1393-1401. https://doi.org/10.1126/science.1123013.

Postberg, F., Khawaja, N., Abel, B., Choblet, G., Glein, C. R., Gudipati, M. S., et al. (2018). Macromolecular organic compounds from the depths of Enceladus. Nature, 558(7711), 564. https://doi.org/10.1038/s41586-018-0246-4.

Rhoden, A. R., Hurford, T. A., Spitale, J., Henning, W., Huff, E. M., Bland, M. T., \& Sajous, S. (2020). The formation of Enceladus' Tiger Stripe Fractures from eccentricity tides. Earth and Planetary Science Letters, 544, 116389. https://doi.org/10.1016/j.epsl.2020.116389

Robidel, R., Le Mouélic, S., Tobie, G., Massé, M., Seignovert, B., Sotin, C., \& Rodriguez, S. (2020). Photometrically-corrected global infrared mosaics of Enceladus: New implications for its spectral diversity and geological activity. Icarus, 113848.

Roberts, J. H. (2016). Evolution of the Ice Shell on Enceladus. In Lunar and Planetary Science Conference, 47, 1503.

Rossi, C., Cianfarra, P., Salvini, F., Mitri, G., \& Massé, M. (2018). Evidence of transpressional tectonics on the Uruk Sulcus region, Ganymede. Tectonophysics, 749, 72-87. https://doi.org/10.1016/j.tecto.2018.10.026.

Rossi, C. (2020). Enceladus_block_rotation. Open Science Framework. https://doi.org/10.17605/OSF.IO/RFZHN.

Salvini, F., 2013. The fault zone deformation architecture. In: 40th Workshop of the International School of Geophysics on properties and processes of crustal fault zones, Erice, Italy, pp. 18-24. ftp://ingv.it/pro/web_ingv/Erice2013_40th\%20Course.pdf/Salvini_Erice2013.pdf.

Salvini, F., 1985. Slope-intercept-density plots - a new method for line detection in images. In: International Geoscience and Remote Sensing Symposium (IGARSS'85), Amherst, MA, pp. $715-720$.

Salvini, F., Billi, A., \& Wise, D. U. (1999). Strike-slip fault-propagation cleavage in carbonate rocks: the Mattinata Fault Zone, Southern Apennines, Italy. Journal of Structural Geology, 21(12), 1731-1749. https://doi.org/10.1016/S0191-8141(99)00120-0.

Salvini, F., \& Storti, F. (2005). Kinematically-versus dynamically induced brittle deformations: the Chinese box ambiguity and solution. Application to the Antarctica Cenozoic Tectonics, European Geosciences Union. In Geophysical Research Abstracts, 7.

Schenk, P. M., \& McKinnon, W. B. (2009). One-hundred-km-scale basins on Enceladus: Evidence for an active ice shell. Geophysical Research Letters, 36, L16202. https://doi.org/10.1029/2009GL039916.

This article is protected by copyright. All rights reserved. 
Scipioni, F., Schenk, P., Tosi, F., D'Aversa, E., Clark, R., Combe, J. P., \& Dalle Ore, C. M. (2017). Deciphering sub-micron ice particles on Enceladus surface. Icarus, 290, 183-200. https://doi.org/10.1016/j.icarus.2017.02.012.

Sekine, Y., Shibuya, T., Postberg, F., Hsu, H. W., Suzuki, K., Masaki, Y., et al. (2015). Hightemperature water-rock interactions and hydrothermal environments in the chondrite-like core of Enceladus. Nature communications, 6(1), 1-8. https://doi.org/10.1038/ncomms9604

Souček, O., Běhounková, M., Čadek, O., Hron, J., Tobie, G., \& Choblet, G. (2019). Tidal dissipation in Enceladus' uneven, fractured ice shell. Icarus, 328, 218-231.

https://doi.org/10.1016/j.icarus.2019.02.012.

Spencer, J. R., \& Nimmo, F. (2013). Enceladus: An active ice world in the Saturn system. Annual Review of Earth and Planetary Sciences, 41, 693-717.

Spencer, J. R., Pearl, J. C., Segura, M., Flasar, F. M., Mamoutkine, A., Romani, P., et al. (2006). Cassini encounters Enceladus: Background and the discovery of a south polar hot spot. science, 311(5766), 1401-1405. https://doi.org/10.1126/science.1121661.

Tajeddine, R., Soderlund, K. M., Thomas, P. C., Helfenstein, P., Hedman, M. M., Burns, J. A., \& Schenk, P. M. (2017). True polar wander of Enceladus from topographic data. Icarus, 295, 4660. https://doi.org/10.1016/j.icarus.2017.04.019.

Tavani S., Storti F., Fernandez O., Munoz J. A., Salvini F. (2006). 3-D deformation pattern analysis and evolution of the Anisclo anticline, southern Pyrenees. Journal of Structural Geology 28, 695-712. https://doi.org/10.1016/j.jsg.2006.01.009

Thomas, P. C., Burns, J. A., Helfenstein, P., Squyres, S., Veverka, J., Porco, C., et al. (2007). Shapes of the saturnian icy satellites and their significance. Icarus, 190(2), 573-584. https://doi.org/10.1016/j.icarus.2007.03.012.

Thomas, P.C., Tajeddine, R., Tiscareno, M.S., Burns, J.A., Joseph, J., Loredo, T.J., et al. (2016). Enceladus's measured physical libration requires a global subsurface ocean. Icarus 264, 37-47. https://doi.org/10.1016/j.icarus.2015.08.037.

Tobie, G. (2015). Planetary science: Enceladus' hot springs. Nature, 519(7542), 162-163. https://doi.org/10.1038/519162a.

Tobie, G., Čadek, O., \& Sotin, C. (2008). Solid tidal friction above a liquid water reservoir as the origin of the south pole hotspot on Enceladus. Icarus, 196(2), 642-652. https://doi.org/10.1016/j.icarus.2008.03.008.

Turcotte, D. L., \& Schubert, G. (2014). Geodynamics. Third edition. Cambridge, UK, Cambridge university press. isbn: 978-0-521-18623-0.

This article is protected by copyright. All rights reserved. 
Waite, J. H., Glein, C. R., Perryman, R. S., Teolis, B. D., Magee, B. A., Miller, G., et al. (2017). Cassini finds molecular hydrogen in the Enceladus plume: evidence for hydrothermal processes. Science, 356(6334), 155-159. https://doi.org/10.1126/science.aai8703

Wise, D.U. (1982). Linesmanship and the practice of linear geo-art. Geological Society of America Bullettin 93(9), 886-888. https://doi.org/10.1130/00167606(1982)93<886:LATPOL>2.0.CO;2.

Wise, D.U., Funiciello, R., Parotto, M., \& Salvini, F. (1985). Topographic lineament swarms: clues to their origin from domain analysis of Italy. Geol. Soc. Am. Bull. 96(7), 952-967. https://doi.org/10.1130/0016-7606(1985)96<952:TLSCTT>2.0.CO;2.

Woodward, N. B., Boyer, S. E., \& Suppe, J. (1989). Balanced geological cross-sections: An EssentialTechnique in Geological Research and Exploration, Am. Geophys. Union, Short Course Geol. 6, 132, Washington,D. C.

Yin, A., \& Pappalardo, R.T. (2015). Gravitational spreading, bookshelf faulting, and tectonic evolution of the South Polar Terrain of Saturn's moon Enceladus. Icarus 260, 409-439. https://doi.org/10.1016/j.icarus.2015.07.017. 


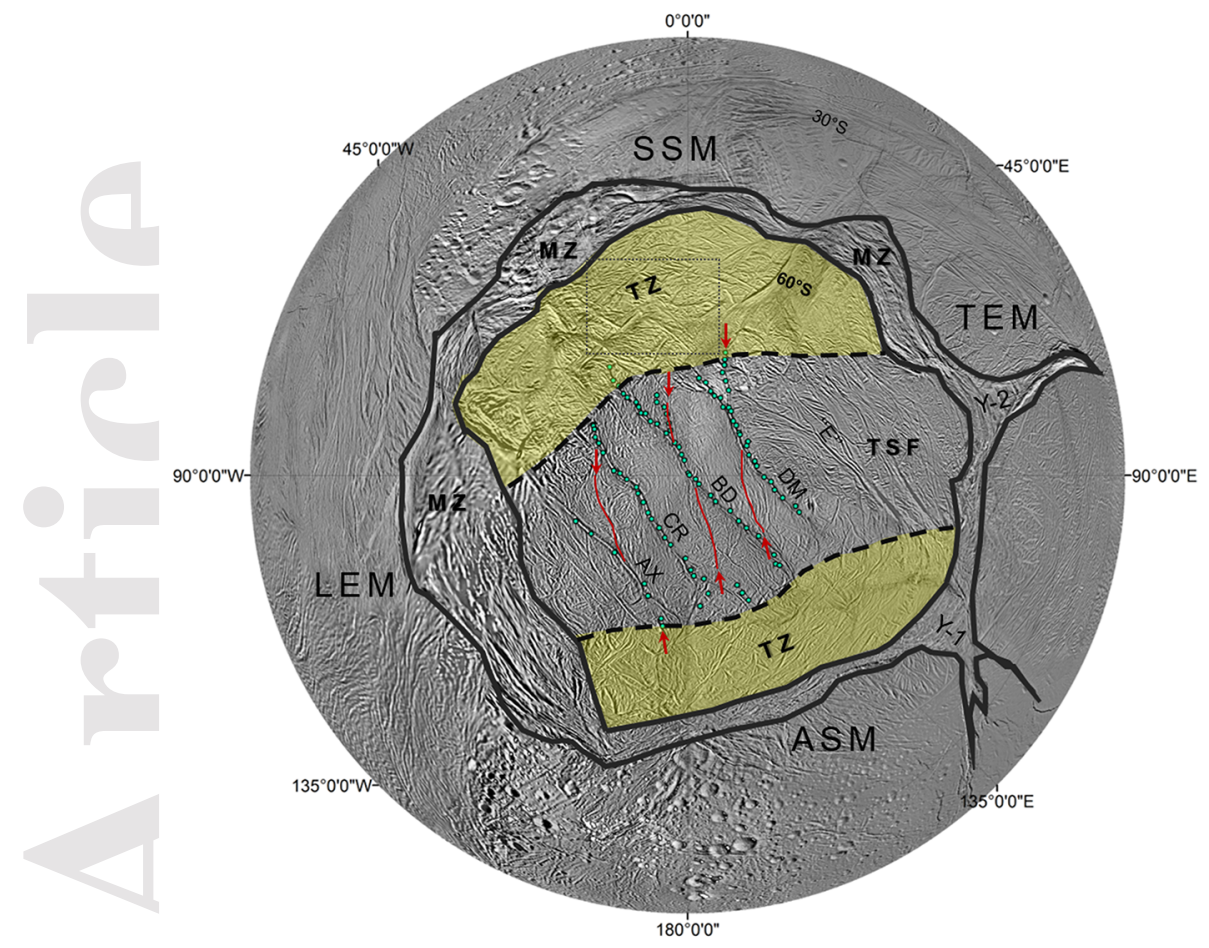

This article is protected by copyright. All rights reserved. 


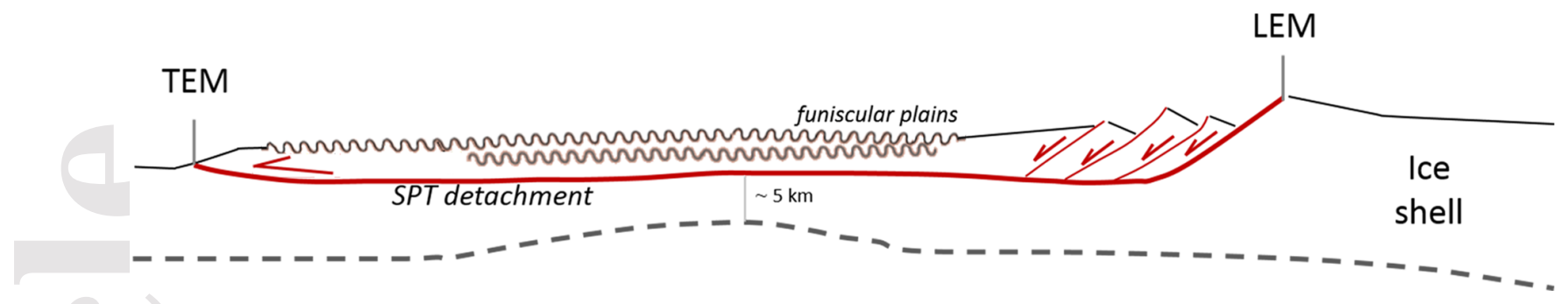

This article is protected by copyright. All rights reserved. 


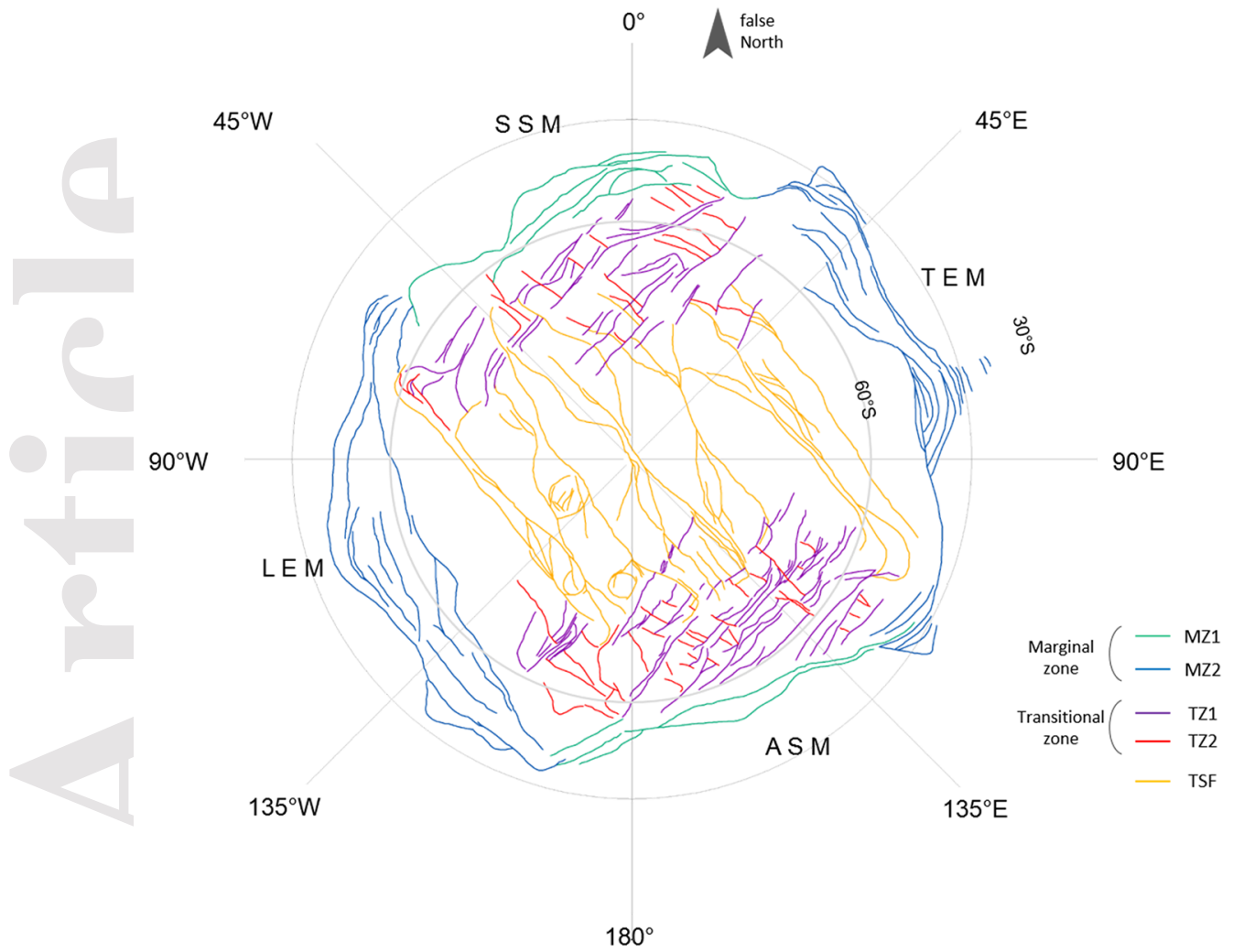

This article is protected by copyright. All rights reserved. 


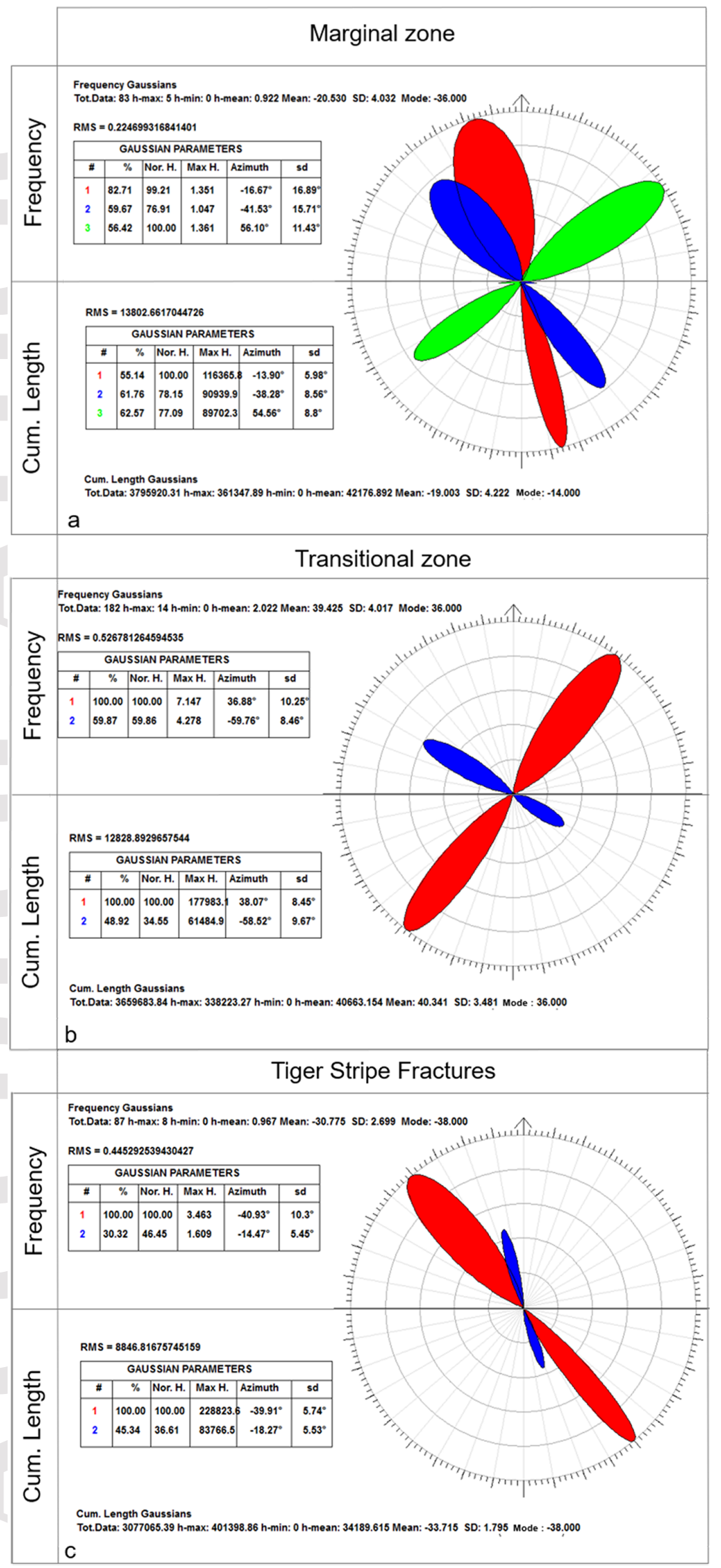

This article is protected by copyright. All rights reserved. 


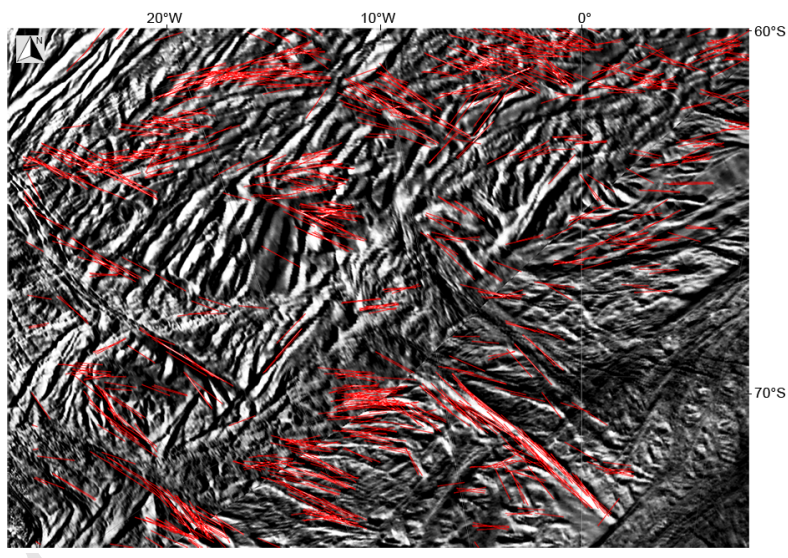

This article is protected by copyright. All rights reserved. 


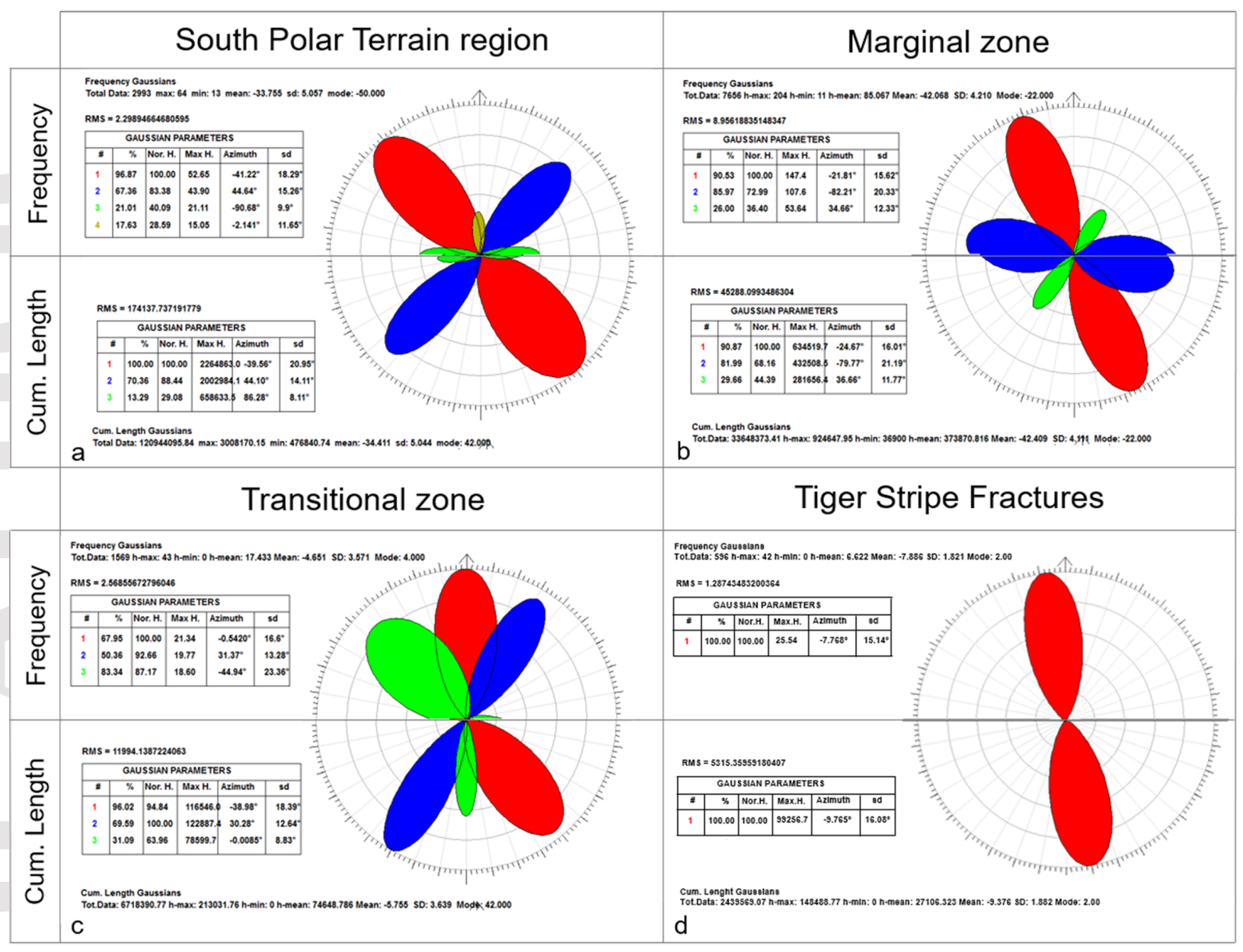

This article is protected by copyright. All rights reserved. 


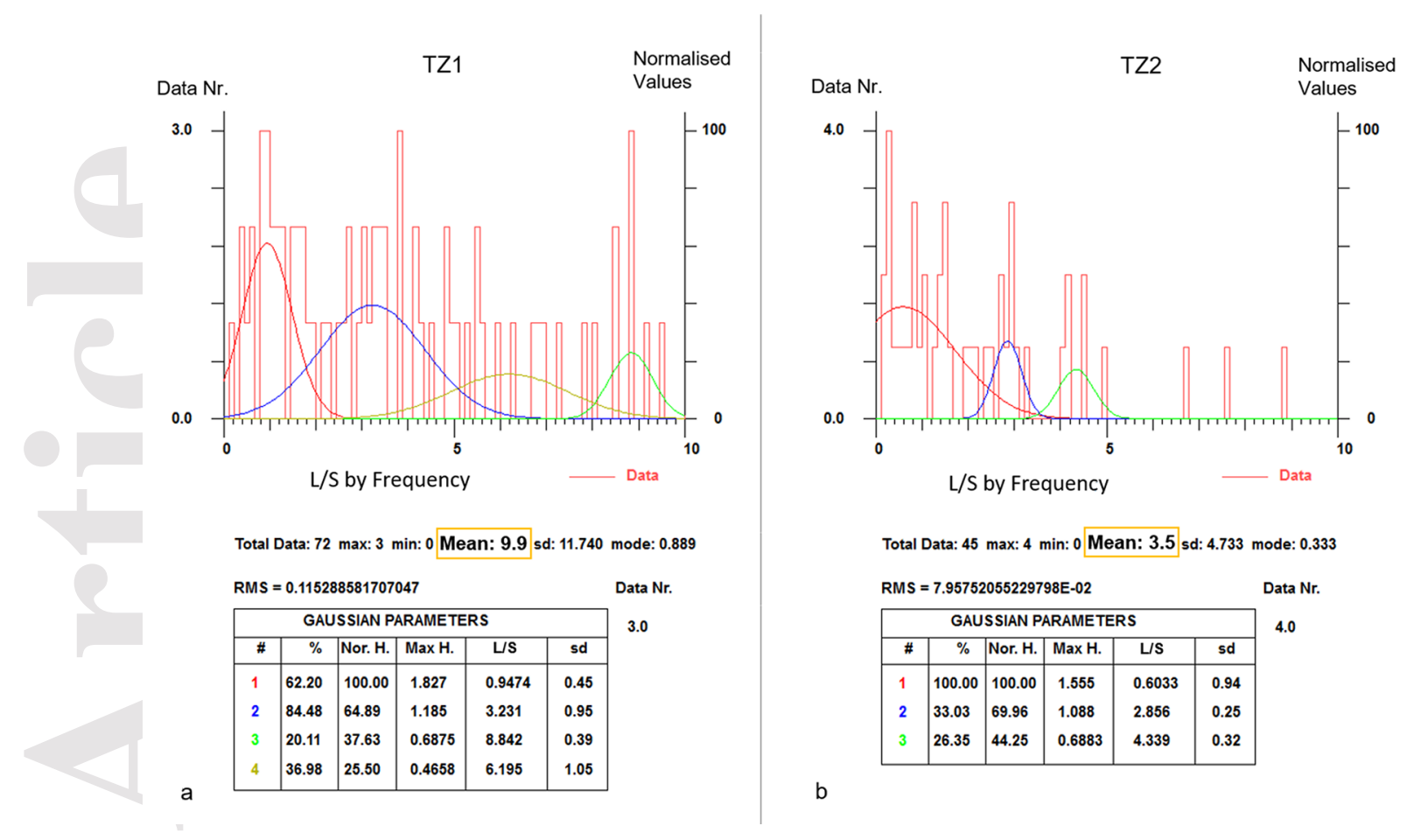

This article is protected by copyright. All rights reserved. 

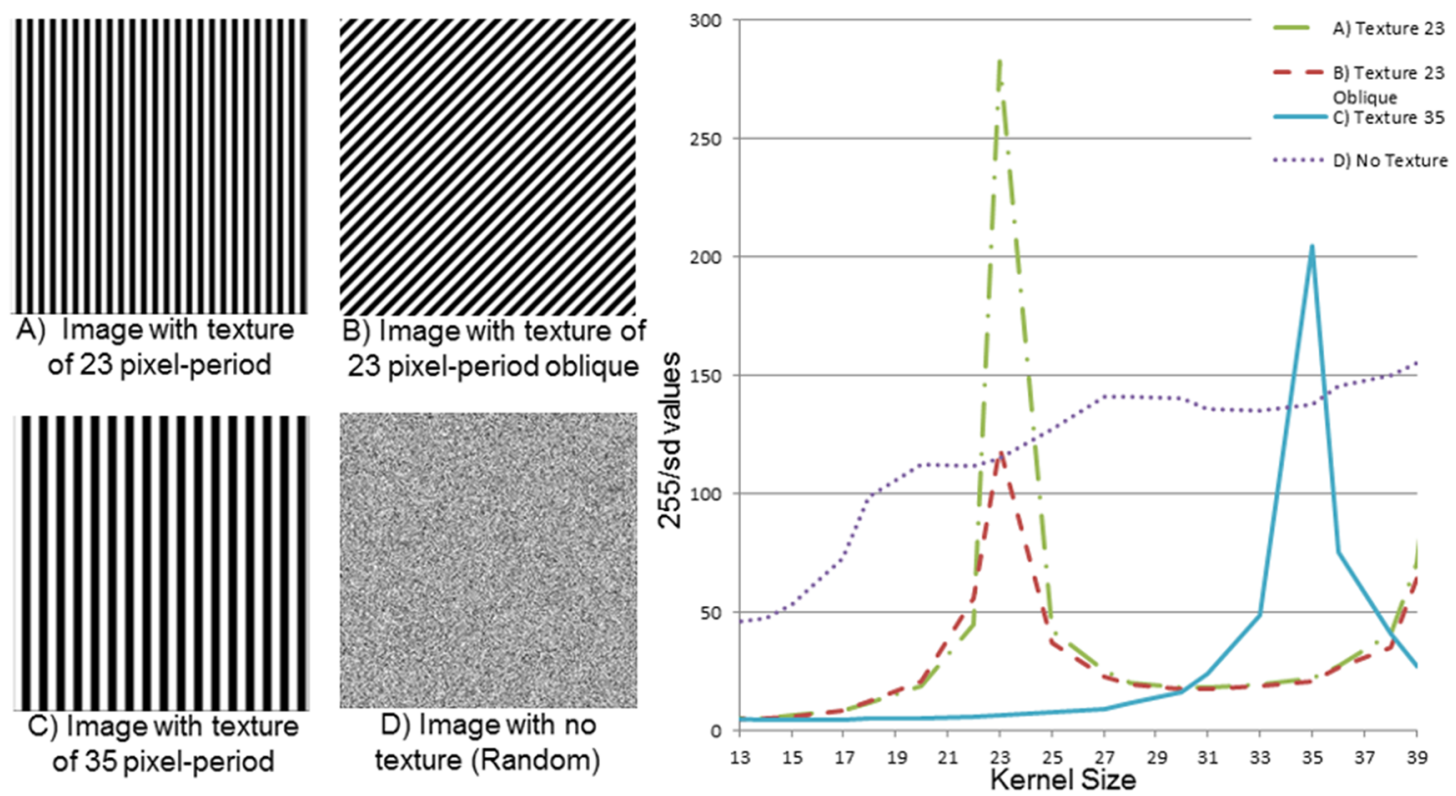

This article is protected by copyright. All rights reserved. 


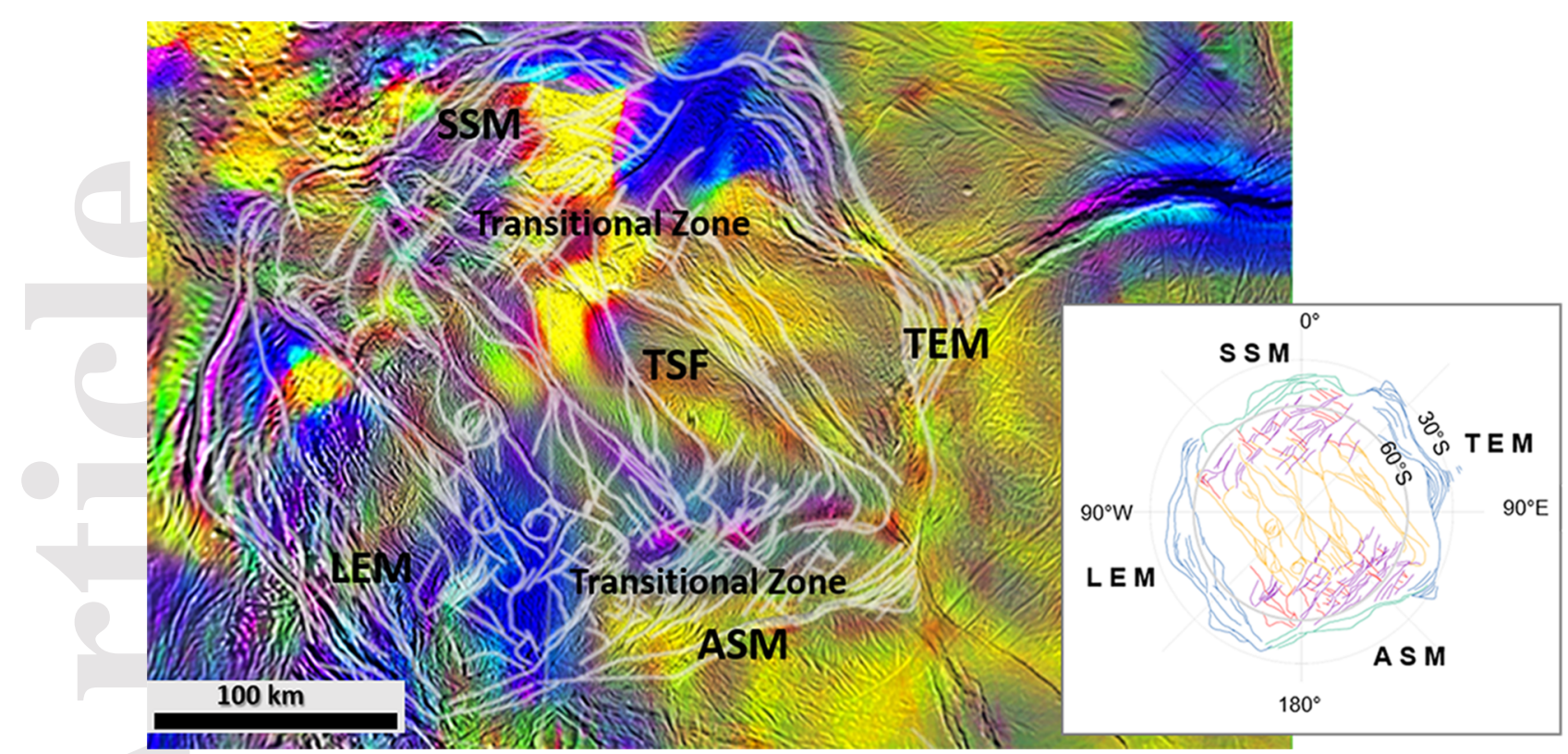

This article is protected by copyright. All rights reserved. 


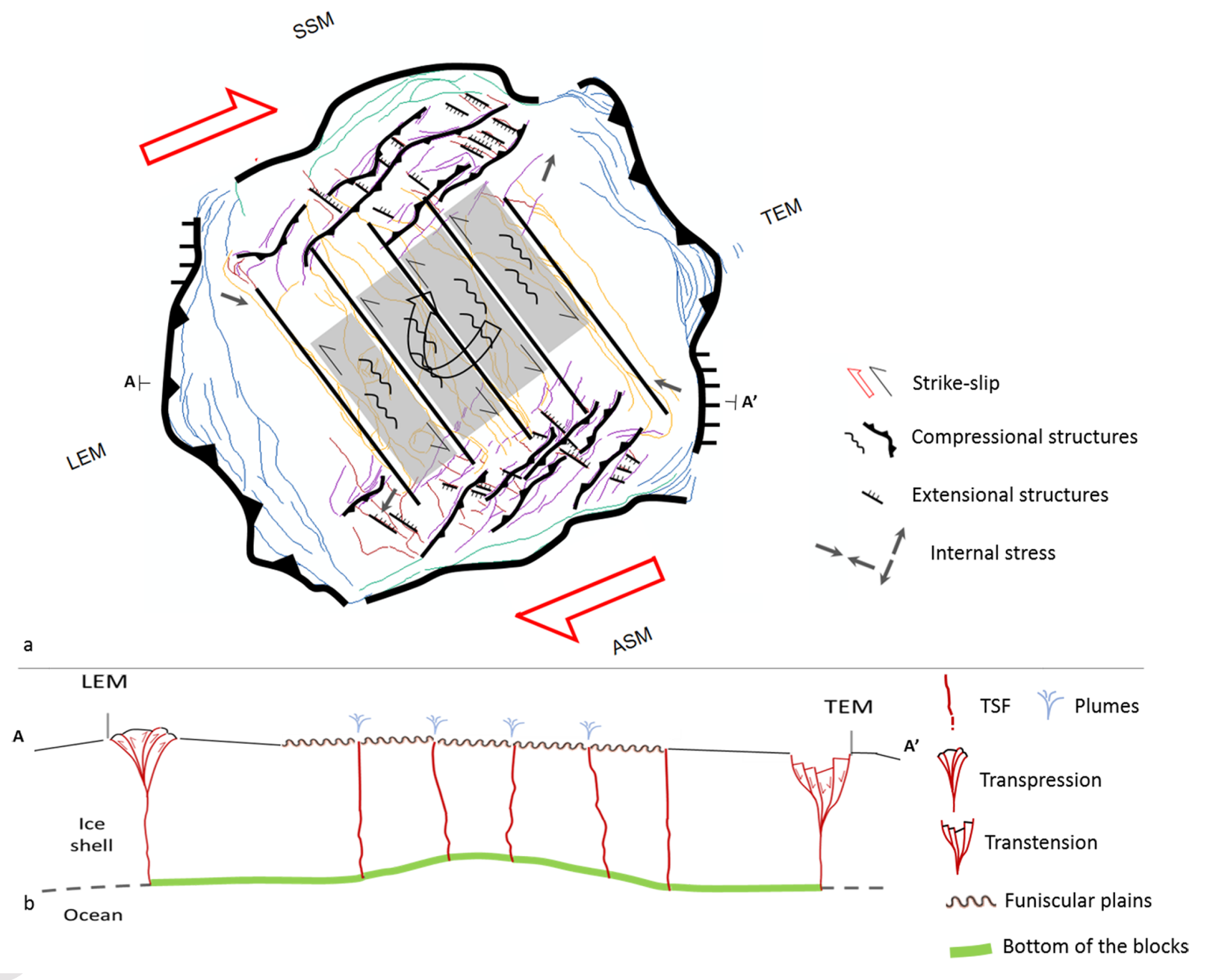

This article is protected by copyright. All rights reserved. 


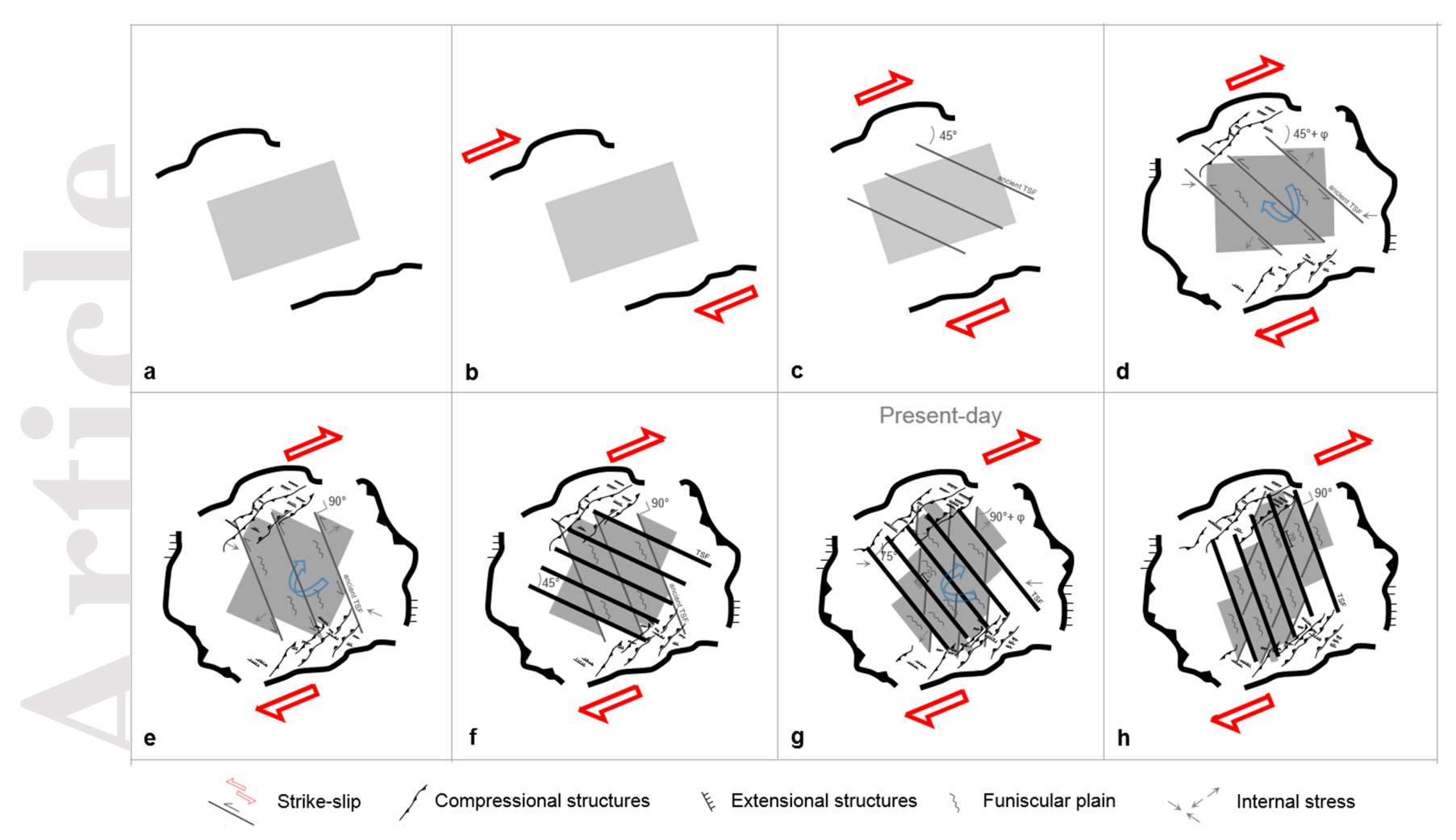

This article is protected by copyright. All rights reserved. 